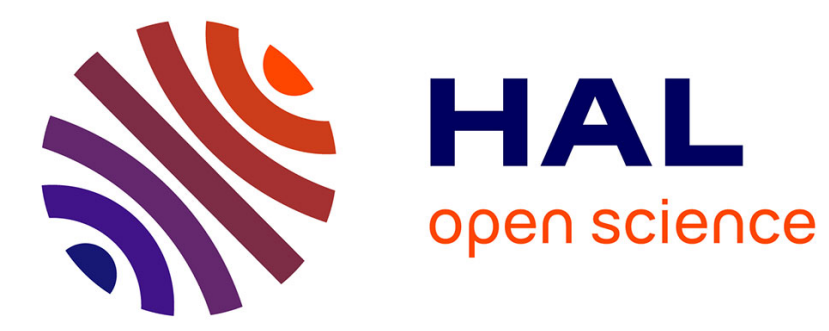

\title{
Estimating habitat loss due to wind turbine avoidance by bats: Implications for European siting guidance
}

Kévin Barré, Isabelle Le Viol, Yves Bas, Romain Julliard, Christian Kerbiriou

\section{To cite this version:}

Kévin Barré, Isabelle Le Viol, Yves Bas, Romain Julliard, Christian Kerbiriou. Estimating habitat loss due to wind turbine avoidance by bats: Implications for European siting guidance. Biological Conservation, 2018, 226, pp.205-214. 10.1016/j.biocon.2018.07.011 . hal-01921448

\section{HAL Id: hal-01921448 \\ https://hal.sorbonne-universite.fr/hal-01921448}

Submitted on 13 Nov 2018

HAL is a multi-disciplinary open access archive for the deposit and dissemination of scientific research documents, whether they are published or not. The documents may come from teaching and research institutions in France or abroad, or from public or private research centers.
L'archive ouverte pluridisciplinaire HAL, est destinée au dépôt et à la diffusion de documents scientifiques de niveau recherche, publiés ou non, émanant des établissements d'enseignement et de recherche français ou étrangers, des laboratoires publics ou privés. 
Estimating habitat loss due to wind turbine avoidance by bats: implications

\section{for European siting guidance}

Kévin Barré $^{1,2,3}$, Isabelle Le Viol ${ }^{1,2}$, Yves Bas ${ }^{1,4}$, Romain Julliard ${ }^{1}$, Christian Kerbiriou ${ }^{1,2}$

${ }^{1}$ Muséum national d'Histoire naturelle, Centre d'Ecologie et des Sciences de la Conservation, UMR 7204 MNHN-CNRS-UPMC, 61 rue Buffon, 75005 Paris, France

${ }^{2}$ Muséum national d'Histoire naturelle, Station de Biologie Marine, 1 place de la Croix, 29900 Concarneau, France

${ }^{3}$ Agrosolutions, 83 Avenue de la Grande Armée, 75782 Paris, France

${ }^{4}$ Centre d'Ecologie Fonctionnelle et Evolutive, UMR 5175, CNRS, 1919 route de Mende, 34293 Montpellier, France

Mailing addresses: ileviol@mnhn.fr; julliard@mnhn.fr; ybas@mnhn.fr;

christian.kerbiriou@mnhn.fr

Corresponding author: Kévin Barré - kevin.barre@edu.mnhn.fr -01 40793831 


\begin{abstract}
Wind energy is rapidly growing as a renewable source of energy but is not neutral for wildlife, especially bats. Whereas most studies have focused on bat mortality through collision, very few have quantified the loss of habitat use resulting from the potential negative impact of wind turbines, and none of them for hub heights higher than $55 \mathrm{~m}$. Such impacts could durably affect populations, creating a need for improvement of knowledge to integrate this concern in implementation strategies. We quantified the impact of wind turbines at different distances on the activity of 11 bat taxa and 2 guilds. We compared bat activity at hedgerows (207 sites) located at a distance of 0-1000 m from wind turbines ( $\mathrm{n}=151)$ of 29 wind farms in an agricultural region in the autumn (overall 193980 bat passes) using GLMMs. We found a significant negative effect of proximity to turbines on activity for 3 species (Barbastella barbastellus, Nyctalus leisleiri, Pipistrellus pipistrellus), 2 speciesgroups (Myotis spp., Plecotus spp.) and 2 guilds (fast-flying and gleaner). Bat activity within $1000 \mathrm{~m}$ of wind turbines by gleaners and fast-flying bats is reduced by $53.8 \%$ and $19.6 \%$, respectively. Our study highlighted that European recommendations (at least $200 \mathrm{~m}$ from any wooded edge) to limit mortality events likely strongly underestimate the loss of bat activity. The current situation is particularly worrying, with $89 \%$ of 909 turbines established in a region that does not comply with recommendations, which themselves are far from sufficient to limit the loss of habitat use.
\end{abstract}

Key words: acoustic monitoring; avoidance; chiroptera; habitat loss; hedgerows; wind energy 


\section{Introduction}

Land consumption due to the development of projects (e.g., transport infrastructure, power generation infrastructure, and urbanization) is a major driver of biodiversity loss (Maxwell et al. 2016). Project developers should avoid and reduce their negative impacts on biodiversity as much as possible and implement offset measures when residual effects persist (mitigation hierarchy, EC 2007). Assessment studies before projects are set up aim to quantify impacts (i.e., direct loss of individuals and future habitat losses) in order to apply the mitigation hierarchy. Most of these studies mainly focus on habitat losses; however, wind farms are an exception because of weak rights of way in the construction stage and growing concerns about impacts to wildlife issues in the post-construction stage (Gibson et al. 2017).

Indeed, a large number of studies summarized by Arnett et al. (2016) have shown that wind farms have adverse effects on bats through mortality events from collisions in the postconstruction stage and could threaten population viability (Frick et al. 2017). Whereas many studies have focused on bat mortality through collision with wind turbines, few have studied activity loss in the post-construction stage resulting from the potential impact on habitat use around wind farms. Habitat availability, notably foraging habitat, is nevertheless recognized as a major driver of population dynamics for most taxa (Ney-nifle \& Mangel 2000; Rybicki \& Hanski 2013; Froidevaux et al. 2017). The establishment of such infrastructure, by modifying environmental conditions, may thus durably affect the habitat use of such long-lived species. Moreover, agricultural landscapes are widely used by bats as foraging areas (Wickramasinghe et al. 2004; Boyles et al. 2011). Indeed, some widespread habitats in agricultural areas are known to be essential for bats, such as wetlands (Sirami et al. 2013) and hedgerows (Lacoeuilhe et al. 2016), structuring the landscape used by bats (Boughey et al. 2011a; FreyEhrenbold et al. 2013). 
To our knowledge, only 2 studies have dealt with the impact of the distance of wind turbines on the attractiveness of foraging habitat, and they studied small turbines $(<25 \mathrm{~m}$ hub height). Indeed, Minderman et al. $(2012,2017)$ found a significant reduction of activity for Pipistrellus pipistrellus and no effect for Pipistrellus pygmaeus (2 species studied) up to 400 $\mathrm{m}$ from the turbines (between 6 and $25 \mathrm{~m}$ hub height). Two other studies have shown a strong reduction in bat activity with proximity to wind turbines without account for impact distances. First, Millon et al. (2014) showed a significantly lower global bat activity within European intensive agricultural fields under wind turbines of $100 \mathrm{~m}$ hub height than in fields away from any turbines. Then, the same authors showed a significantly lower activity (20 times in mean) at wind turbine sites (between 50 and 55 hub height) for Miniopterus sp. and Chalinolobus sp. in an island tropical context (Millon et al. 2018). Thus, concerning the standard turbines $(>55$ $\mathrm{m}$ hub height), there has been no accurate assessment of the distance and the magnitude of the wind turbine impact on the attractiveness of foraging habitat. In addition, overall very few species have been studied in relation to these questions. Another great issue is the reduction of the mortality risk by setting up wind turbines far from attractive habitats such as wooded edges, including hedgerows (Boughey et al. 2011a; Lacoeuilhe et al. 2016). Indeed, hedgerows in agricultural landscapes concentrate most of the activity for the majority of bat species, which becomes very low at more than $200 \mathrm{~m}$ from hedgerows in open areas (Kelm et al. 2014). Guidelines of the Agreement on the Conservation of Populations of European Bats (UNEP/EUROBATS) have recommended since 2008 that turbines should not be installed closer than $200 \mathrm{~m}$ to any types of wooded edges (forests and hedgerows) due to the high risk of fatalities (Rodrigues et al. 2015). However, these recommendations only consider the avoidance of collision and are based on the observation of reduced activity with increased distances to wooded edges. Reduction of activity in habitats close to turbines as well as the threshold distance of this impact are not considered in recommendations. 
Moreover, the installed capacity of wind energy has rapidly grown as a renewable energy source over the last 10 years by a factor of 6.6 (Global Wind Energy Council 2016). This strong positive trend is expected to continue. Indeed, the 2015 United Climate Change Conference (COP 21) in Paris signed by 195 countries reinforced the development of renewable energy, in which wind energy occupies an important place. The main wind farms are developed in intensive agricultural areas to avoid urban areas and habitats of conservation concern such as forests.

In this context, there is an urgent need for a more specific approach to assess the potential decrease in bat activity close to wind turbines in order to quantify the changes of habitat use and the distance of impact. This possible underestimated impact of wind turbines could constitute an important concern, affecting population dynamics with a loss of habitat availability (Rodrigues et al. 2015). Indeed, negative impacts on activity around turbines result in a net loss of habitat for bats, which is currently not quantified. Such an approach of assessing the loss of bat activity due to the establishment of new structures could also be helpful to define ecological equivalences in the context of avoidance and offset measures (Millon et al. 2015). This obviously implies being able to assess species-specific loss of activity according to the distance to wind turbines.

We assessed the impact of wind turbines on the bat activity ( 8 species, 3 species groups and 2 guilds) in a habitat well-recognized for its importance for the species. We designed a study recording bat activity on hedgerows along a uniform gradient of distance (0$1000 \mathrm{~m}$ ) from 151 turbines of 29 wind farms. Such a design allowed us to evaluate the current loss of activity according to the distance from turbines that can be attributed to their presence. Finally, we also assessed how the European recommendations are applied so far, and the underlying linear of deserted hedgerows by bats that this involves. 


\section{Methods}

\subsection{Study area}

Data were collected at 29 wind farms for a total of 151 turbines across two regions in northwest France (Figure 1), representing 16.6\% of the 909 installed turbines in these regions. All wind farms were composed of 3 to 11 turbines (mean 5.2) of $84 \mathrm{~m}$ (standard deviation 12 m) in hub height. For each farm, all turbines had the same height. The installed wind energy capacity in the studied regions was $12141 \mathrm{MW}$, representing $13.8 \%$ of the national installed capacity and covering $5.1 \%$ of the electricity needed in these regions (RTE 2017). The study regions are dominated by agricultural areas $(82.2 \%)$, whose arable land and grassland compose 48 and $34.2 \%$ of the land area, respectively. Urban areas, mainly characterized by villages and small cities, only represent $6.1 \%$, and forests and wetlands cover 10.6 and $1.1 \%$, respectively.

The precise location (geographical coordinates) and establishment date of the studied 909 wind turbines were known thanks to information from the French environmental authority.

\subsection{Sampling design and bat data}

We studied bat activity at hedgerows along a uniform gradient distance of 0 to $1000 \mathrm{~m}$ from the nearest wind turbine (Figure 2) through recordings of echolocation calls on 207 sites distributed around the 151 wind turbines of the 29 farms studied in operation. Wind farms were selected by minimizing the landscape heterogeneity and optimizing the variation in the distance of hedgerows from turbines. We defined sites for a given wind farm in order to minimize differences in the hedgerow quality and local surrounding habitats and to facilitate accessibility. Only one site per hedgerow was sampled, only once, and sites were separated by at least $300 \mathrm{~m}$ from each other. We simultaneously sampled 5-13 sites (average $=9$ ) per night, 
covering a uniform gradient of available distances from the nearest turbines (Table A.1).

Sampling was carried out using bat acoustic records over 23 nights from the $7^{\text {th }}$ of September to the $8^{\text {th }}$ of October 2016 during the migration period (Voigt et al. 2015, 2016). Among the 23 nights, 14 were dedicated to the sampling of only one wind farm per night, while the other 9 nights allowed us to simultaneously sample 2 wind farms per night (these wind farm were in average $8.1 \mathrm{~km}$ distant).

Recordings were performed during the entire night, from 30 minutes before sunset to 30 minutes after sunrise. Standardized echolocation calls were recorded using one SM2BAT recorder per site. The detectors automatically recorded all ultrasounds that were $6 \mathrm{~dB}$ over the background noise, ensuring a large detection range. SMX-US microphones were placed at a height of $1.50 \mathrm{~m}$ from the ground and oriented upward on a vertical axis.

Since it is impossible to determine the number of individual bats from their echolocation calls, we calculated a bat activity metric (bat passes), calculated as the number of contacts per night per species. Thus, a bat pass was defined as a single or greater echolocation call within a 5-second interval. This interval is considered a good compromise according to bat pass duration among species (Millon et al. 2015). In a first step, echolocation calls were detected and classified to the most accurate taxonomic level, allowing us to assign a confidence index to each bat pass using the software TADARIDA (Bas et al. 2017). In a second step, we performed a manual validation of the automatic identification. A sample of 1811 bat passes of 10 species and 2 groups were randomly double checked manually by KB and YB using the BatSound $\odot$ software. A mean of $18(\mathrm{SD}=10)$ bat passes per class of the confidence index for each species and group were checked, except for Rhinolophus species, where all passes were checked due to the low total number (Table A.2). Based on the results of these manual checks, we performed a logistic regression between the success/failure of automatic species assignation (binomial response variable) and the confidence index of the 
automatic identification (explanatory variable) for each species or group. This allowed us to predict the needed confidence index from the automatic identification process to tolerate a given maximum error risk (Figure A.1). Then, we filtered the bat dataset on 5 confidence index thresholds corresponding to a predicted maximum error risk between 0.5 and 0.1 (Table A.3) in order to perform analyses on different thresholds of maximum error risk tolerance and check the consistency of the results.

Three groups (Pipistrellus kuhlii/nathusi, Plecotus spp. and Myotis spp.) were constructed because species within these groups were difficult to distinguish from each other, except one species of Myotis spp., Myotis nattereri, for which echolocation calls are most often characteristic (Siemers \& Schnitzler 2000; Obrist et al. 2004; Barataud 2015). We also constructed 2 functional groups, the fast-flying species guild, containing Barbastellus, Pipistrellus, Eptesicus and Nyctalus genera known to fly along wooded edges and in nearby open environments, and the gleaner species guild, containing Plecotus and Rhinolophus genera, as well as Myotis nattereri, known to fly in cluttered environments (Schnitzler \& Kalko 2001). We did not include Myotis spp. in the gleaner species guild due to the diversity of flight behaviours (not always in cluttered environments) of the remaining undetermined species (Schnitzler \& Kalko 2001; Schaub \& Schnitzler 2007).

\subsection{Environmental covariates}

We selected 7 environmental covariates (the distance to wetlands, forests and urban areas; proportion of arable land, grassland and forest; and length of hedgerows) known as good predictors of bat activity for the species studied (Boughey et al. 2011; Lacoeuilhe et al. 2016) and which showed enough variability (Table 1). The proportion or length of these environmental covariates was calculated within a 250, 500, 750 and 1000 m radius around the sampling sites in order to use the best scale when selecting those with the smallest Akaike 
Information Criteria (AIC). Recent landscape data (2016) were provided by the National Institute of Geography (from BD TOPO for data on forests and urban areas, from BD Carthage for wetland data, from BD ORTHO for manual digitization of hedgerows and from Graphical Parcel Register for arable and grass land data (www.ign.fr); distances, lengths and proportions were calculated using ArcGIS 10.0).

The precise location of wind turbines also allowed us to calculate the current distance to the nearest wooded edge (forest or hedgerow) for each turbine in order to describe the current situation with respect to 2008 EUROBATS recommendations.

\subsection{Statistical analysis}

We assessed whether bat activity of species or groups recorded at hedgerows differed according to the distance to the nearest wind turbine using a Generalized Linear Mixed Model (GLMM, R package lme4). According to the nature of the response variable (i.e., number of bat passes) and potential over-dispersion, we chose the best error distribution among Poisson or negative binomial distributions (Zuur et al. 2009).

We included the distance to the nearest wind turbine and the 7 environmental covariates in the models as fixed effects. All variables used in the models were scaled to allow direct comparisons (Schielzeth 2010). We included interactions between the distance to the nearest wind turbine variable and land cover variables (arable land, grass land and forest proportions, and length of hedgerows) in order to assess the landscape dependence of the wind turbine effects. According to the sampling design (i.e., simultaneous recordings of bat activity along a continuous distance to the nearest wind turbine the same night), we included the date in the models as a discrete random effect to control for inter-night variations (e.g., landscape context, weather conditions). Since only one wind farm was sampled per date, rarely two when they were very close, it was not possible to perform models containing, as 
fixed effects, the farm characteristics, such as height and number of turbines, which were confounded in the random effect. In addition, these characteristics had a low variability (see study area section). For the fast-flying and gleaner species models, we added the species composing the guild as a second random effect in order to take into account abundance variations among species.

Models were performed on data selected at confidence indices corresponding to a 0.5 maximum error risk tolerance under which data were discarded. This allowed us to conserve a maximum number of bat passes and species occurrences in models (Table A.3). The results were also confirmed at the higher restrictive threshold of confidence indices minimizing the maximum error risk tolerance (0.1) for a majority of species for which data at such a threshold were sufficient (number of bat passes and occurrences).

Full models were constructed by checking correlations between environmental covariates and the distance to the nearest wind turbine and between environmental covariates (Table B.1). We detected a correlation between arable land and grassland covariates $(r>0.7)$; therefore, they were not simultaneously included in the modelling procedure using the dredge function (R package MuMIn). The potential non-linear effect of the distance to the nearest wind turbine was checked by visual inspection of the plot from Generalized Additive Mixed Models (GAMM, R package $m g c v$ ). We detected a quadratic relationship for $N$. leisleri and Nyctalus noctula (Figure B.1); we therefore took this into account in GLMMs for these species by adding a quadratic effect for the distance to wind turbine variable. We checked that no multicollinearity problems occurred by performing variance-inflation factors (VIF) using the corvif function (R package $A E D$; Zuur et al. 2010) on each full model. All variables showed a VIF value $<2$, meaning there was no striking evidence of multicollinearity (Chatterjee \& Hadi 2006). Then, we generated from full models a set of candidate models containing all possible variable combinations ranked by corrected AIC 
(AICc) using the dredge function. For each set of candidate models, we performed multimodel inference averaging on a delta $\mathrm{AICc}<2$ using the model.avg function to obtain an averaged regression coefficient for each fixed effect (R package MuMIn, Barton, 2015). We used the allEffects function (R package effects) to get the predicted number of bat passes shown in Figure 3. From these predictions, we calculated the percentage of lost bat passes as a percentage of the maximum predicted activity for a given species/group. The relative importance of variables as well as the number of candidate models selecting each variable were extracted from the dredge procedure. We also checked the non-spatial autocorrelation of residuals of each best model using the dnearneigh and sp.correlogram functions associated with Moran's I method by visual inspection and significance tests (R package spatial, Moran, 1950). We did not detect any problem from the over-dispersion ratio on full and best models $(<1.28$; Table B.2). Models were validated by visual examination of residual plots. Since some species had low occurrences, which may cause statistical problems, we confirmed the results of the distance to wind turbine variable by confronting models with and without covariates. All analyses were performed using a significant threshold of 5\% in the R statistical software v.3.3.1.

\subsection{Applied quantification of the loss of hedgerow use by bats}

For our results could be easily transferable to stakeholders (i.e., for loss quantification and offset sizing), we proposed a representation of the impacts on activity. We converted the cumulative loss of bat activity at the landscape scale around wind turbines $(1 \mathrm{~km})$ to an equivalent of linear length of deserted hedgerows.

The method presented as an example for a given wind farm in Figure 4 consists of three main phases: 
1) The total length of hedgerows $\left(\sum \mathrm{H}\right)$ in a $1000 \mathrm{~m}$ radius was calculated (step 1; Figure 4).

2) With the aim of accounting for the network of hedgerows (length and distance) in the surroundings of the wind farm, each hedgerow in a $1000 \mathrm{~m}$ radius was segmented by $10 \mathrm{~m}$ sections (steps 2; Figure 4). The distance of each central point of the hedgerow sections to the nearest turbine was calculated (steps 3; Figure 4). Then, we calculated the average distance of all sections. This measure corresponds to the averaged distance $\mathrm{D}$ of all hedgerows to wind turbines $1000 \mathrm{~m}$ around the farm (step 4; Figure 4).

3) Using model predictions (see statistical analysis section), we estimated the corresponding percentage of lost bat activity at this average distance $\mathrm{D}(\%$ pred $\mathrm{D})$. This loss is expressed as the percentage of the maximum predicted activity (i.e., activity at 1000 metres in our study, see Table S2.7). Finally, this loss (\%pred $\left.{ }_{D}\right)$ was multiplied by the total length of hedgerows $(\mathrm{H})$ to get the length of deserted hedgerows by bats (step 5; Figure 4). 


\section{Results}

\subsection{Bat monitoring}

In total, considering a maximum error risk tolerance of 0.5 in the data, 193980 bat passes of 8 species and 3 species groups were recorded in the 207 study sites, where the most abundant species was $P$. pipistrellus, representing $81 \%$ of the observations. The least abundant species were Rhinolophus ferrumequinum (22 bat passes) and N. noctula (25 bat passes), which were present in 7 and $9 \%$ of the study sites, respectively. All other species or groups were present in more than $14 \%$ of the study sites (Table 2).

\subsection{Impact of wind turbines on bat activity}

We detected a significant positive effect of the increasing distance from the nearest wind turbine on the activity of B. barbastellus, Myotis spp., N. leisleri, P. pipistrellus, Plecotus spp., and fast-flying and gleaner species guilds, plus a significant quadratic effect for N. leisleri and a nearly significant quadratic effect for N. noctula (Table 3; Figure 3). This means that the closer a hedgerow was to a wind turbine, the lower was the activity of these species. In contrast, we did not detect any effects for some common (Eptesicus serotinus, Myotis nattereri and Pipistrellus kuhlii/nathusii group) and rare species (Rhinolophus hipposideros and R. ferrumequinum) (Table 3). There were significant positive interactions of the distance to the nearest wind turbine variable with the proportion of forests for Myotis spp, as well as the length of hedgerows for fast-flying and gleaner species guilds. This result suggested that Myotis spp. were mainly recorded in contexts of high forest proportion, in which the negative effect of the distance to the nearest wind turbine was significantly higher than in contexts of lower forest proportion. Similarly, for fast-flying and gleaner species guilds, when the hedgerow length was shorter, the activity was higher far from wind turbines. All top candidate models (delta AICc < 2) showed a lower value of AICc than null models 
(Table B.2). Among all candidate models, the distance to wind turbine variable was always selected, confirming the relative importance of this variable compared to other environmental covariates, except for E. serotinus and Rhinolophus species (Table B.3).

We also evaluated the potential attenuation of the linear effect of the wind turbine distance testing significance of a quadratic effect. We did not found quadratic relationship of distance to the nearest wind turbine, except for $N$. leisleri (Figure 3). Thus, for the most species, the activity remains affected at 1000m from a wind turbine. The lost activity was therefore likely underestimated and occurred at more than $1000 \mathrm{~m}$. Thus, the percentage of lost activity was high, even at long-distances: for instance, at $500 \mathrm{~m}$ from the nearest turbine, we detected activity losses of $57 \%$ and $77 \%$ for $P$. pipistrellus and the gleaner species guild, respectively (Figure 3).

These results were robust no matter the level of uncertainty included in the identifications (i.e., the maximum error risk tolerance). Indeed, we re-ran the analysis using the most restrictive tolerance of maximum error risk in the data selection of the response variable (0.1), and we found mostly no change in the results for most of the species/groups and guilds (Table B.4). We also compared estimates of models with and without covariates (Table B.5). These negative effects of wind turbines on habitat attractiveness appeared to be little influenced by associated environmental covariates since we did not find any changes for most of the species/groups and guilds when covariates were excluded. Only one change was found for E. serotinus, for which the estimate became higher and the p-value significant. This could be caused by the very strong effect of the distance to the urban variable hiding the distance to the nearest wind turbine variable, despite there being no striking correlation between them or problems in VIF. 


\subsection{Current wind turbine establishment and generated loss of hedgerow use by bats}

Among the 909 wind turbines in northwest France, which contained the studied farms, $89 \%$ were established at less than 200 m from any type of wooded edges (forest or hedgerows). The situation was the same after the publication of the EUROBATS recommendations in 2008, which recommended nevertheless the avoidance distance of $200 \mathrm{~m}$ from any type of edges for the establishment of wind turbines (Figure 5).

From these current establishments and with our impact assessment method (Figure 4), making previous statistical results practical for stakeholders, we could quantify the length of deserted hedgerows by bats. Indeed, focusing on the 151 sampled wind turbines, the loss of activity in a $1000 \mathrm{~m}$ radius around turbines for fast-flying and gleaner species guilds was $19.6 \%$ and $53.8 \%$, respectively, corresponding to 145 and $397 \mathrm{~km}$ lengths of deserted hedgerows, respectively. Our 151 studied turbines represent $16.6 \%$ of the total number (909) located in northwest France. Thus, by extrapolation, the total length of deserted hedgerows by bats at this scale would be 872 and $2390 \mathrm{~km}$ for fast-flying and gleaner species guilds, respectively. 


\section{Discussion}

To our knowledge, this study is the first test of the impact distance of tall wind turbines on bat activity. The results highlight a strong negative effect of turbines on activity, occurring even at long distances at least up to $1000 \mathrm{~m}$ for most species, groups and guilds. The negative effect at long distances concerns various species, either fast-flying or gleaner species.

The detected effects are consistent with the few studies dealing with this influence of wind turbines on bat activity (Minderman et al. 2012, 2017, Millon et al. 2015, 2018) and complement them for less intensive agricultural landscapes with high proportions of grasslands and forests that are favourable for bats. Moreover, such a preserved farming landscape constitutes a concern for the conservation of some rare species (e.g., $B$. barbastellus and Rhinolophus species) listed in Annex II of the Habitats Directive 92/43/EEC. The undetected interaction effects of distance with the arable and grassland proportions for all impacted species despite high land-use variability in our data suggest that this negative effect occurs in any agricultural landscape, no matter its composition. However, this result should be confirmed in other more intensive agricultural landscapes.

Negative effects were detected on a wide range of species with highly contrasting ecology and flight behaviour. Some of these species have so far been poorly taken into consideration in environmental studies for wind farm establishment due to a low collision risk (Roemer et al. 2017), thus reinforcing the significance of our findings. Indeed, $B$. barbastellus, Plecotus spp. and Myotis spp. had a very low level of collision susceptibility index with turbines, taking into account the species abundance (Roemer et al. 2017). However, we did not detect any relationship between the distance to the nearest wind turbine and the Pipistrellus kuhlii/nathusii group, which is comprised of a migrant resident species and a long-range migrant species, with an estimate close to zero and small standard error. 
Flight in migration could be expected to be different, faster and less connected to habitats. Therefore, we hypothesize that this absence of effect could be linked to the coexistence of two behaviours in the group, a negative impact on $P$. kuhlii (i.e., avoidance) and a positive impact (i.e., attractiveness) for $P$. nathusii. In this way, migratory species such as $P$. nathusii should be studied at the species level by studying areas in which $P$. kuhlii is absent, as in some areas in Northern Europe (Ancillotto et al. 2016). Finally, an appropriate design is needed for $E$. serotinus, for which we detected a negative effect of turbines, but statistically masked by the strong correlation with the distance to small urban areas, for instance, by studying this species in a territory where colonies are well known or far from all small urban areas.

The detected negative effects of wind turbines on bat activity in our study could be caused by avoidance. Mechanisms leading to avoidance of wind turbines are still widely unknown and deserve to be evaluated; one of them suggested by Bennett \& Hale (2014) could be the red aviation lights, which were always present in our studied turbines. Noise produced by wind turbines could also constitute another mechanism, in particular for species listening for prey (i.e., passive listening) to find food, which can be highly affected by anthropogenic noise (Schaub et al. 2009).

\section{Implications for wind energy development}

Despite new recommendations in 2008 from EUROBATS, we showed that the recommendation of a minimal distance of $200 \mathrm{~m}$ from woody edges for installing a wind turbine is still far from being considered in most cases. Hence, based on our findings, we first encourage efforts to improve the first step in the application of the mitigation hierarchy proposed by the Business and Biodiversity Offsets Programme, consisting of avoidance by installing turbines as far as possible from edges. Ideally, the EUROBATS recommendation of $200 \mathrm{~m}$ is not sufficient. This implies concentrating wind energy in less sensitive areas for bats, 
far from wooded edges, at more than $1000 \mathrm{~m}$. Reflections should be conducted on the planning of wind energy establishment and on the place of bats in the aim of conciliating agricultural and energy production. Indeed, bats should be considered in this trade-off, considering their huge ecosystem services in agriculture (Boyles et al. 2011; Maine \& Boyles 2015). In addition, for bat conservation, the mitigation of such negative impacts is highly recommended due to the strong links existing between activity (notably foraging activity) indicative of habitat quality and population dynamics. In that case, replanting hedgerows on a length that corresponds to the loss of activity could be a helpful measure (Millon et al. 2015). In addition, such offsets require a calculation of the length of deserted hedgerows by bats for sizing, for which our impact assessment method explained in Figure 4 can be used, making the results transferable to stakeholders. Indeed, such an assessment method aims to improve the positioning of turbines in relation to wooded edges and the quantification of offset hedgerows needed, and it can be easily applied by wind turbine operators. However, this method of estimating the length of deserted hedgerows by bats presents a limitation: It is not a physical loss of hedgerow by removal. This means the hedgerow remains potentially functional for a proportion of bat individuals and for other taxa, such as arthropods. The method to assess the loss of an equivalent linear amount of deserted hedgerows is thus an extrapolation to all hedgerows around a given wind farm and only considers bats in the calculation. In addition, in no case should any hedgerows be removed with the aim of reducing impacts on bat activity. Our study should encourage operators to stop the installation of wind turbines close to wooded edges, and without offsetting when closer than $1000 \mathrm{~m}$ to edges, by objectifying losses and the corresponding need for offsetting. The absence of offsetting so far has led to a length of up to $2400 \mathrm{~km}$ of deserted hedgerows by bats at the study regions' scale. 


\section{Acknowledgements}

This work was supported by DIM ASTREA grants from Region Ile-de-France. We sincerely thank Agrosolutions (agri-environmental expert consulting subsidiary of the InVivo agricultural cooperative group) for funding field study fees.

\section{Authors' Contributions}

$\mathrm{KB}$ and $\mathrm{CK}$ conceived the ideas, $\mathrm{KB}$ designed the methodology and collected the data; KB, CK and YB analysed the data; all authors led the writing of the manuscript. All authors critically contributed to the drafts and gave their final approval for publication. 


\section{References}

Ancillotto, L., Santini, L., Ranc, N., Maiorano, L. \& Russo, D. (2016) Extraordinary range expansion in a common bat: the potential roles of climate change and urbanisation. Science of Nature, 103, 15.

Arnett, E.B., Baerwald, E.F., Mathews, F., Rodrigues, L., Rodriguez-Durán, A., Rydell, J., Villegas-Patraca, R. \& Voigt, C. (2016) Impacts of wind energy development on bats: a global perspective. Bats in the Anthropocene: conservation of bats in a changing world (C. Voigt and T. Kingston, eds.) pp. 295-323. Springer International Publishing AG, Cham, Switzerland.

Barataud, M. (2015) Ecologie Acoustique Des Chiroptères d'Europe, Identification Des Espèces, Étude de Leurs Habitats et Comportements de Chasse, Biotope Ed.

Barton, K. (2015) MuMIn: Multi-Model Inference, http://cran.r-project.org/package=MuMIn Bas, Y., Bas, D. \& Julien, J. (2017) Tadarida: A Toolbox for Animal Detection on Acoustic Recordings. Journal of open research software, 5, 1-8.

Bennett, V.J. \& Hale, A.M. (2014) Red aviation lights on wind turbines do not increase batturbine collisions. Animal Conservation, 17, 354-358.

Boughey, K.L., Lake, I.R., Haysom, K. a. \& Dolman, P.M. (2011a) Improving the biodiversity benefits of hedgerows: How physical characteristics and the proximity of foraging habitat affect the use of linear features by bats. Biological Conservation, 144, $1790-1798$.

Boughey, K.L., Lake, I.R., Haysom, K. a. \& Dolman, P.M. (2011b) Effects of landscape-scale broadleaved woodland configuration and extent on roost location for six bat species across the UK. Biological Conservation, 144, 2300-2310.

Boyles, J.G., Cryan, P.M., McCracken, G.F. \& Kunz, T.K. (2011) Economic importance of bats in agriculture. Science, 332, 41-42. 
Chatterjee, S. \& Hadi, A.S. (2006) Regression Analysis by Example, 5th ed. John Wiley \& Sons, Inc.

European Commission. (2007) Guidance on Habitats Directive Articles 12 and 16. http://ec.europa.eu. Accessed March 2018

Fonderflick, J., Azam, C., Brochier, C., Cosson, E. \& Quékenborn, D. (2015) Testing the relevance of using spatial modeling to predict foraging habitat suitability around bat maternity: A case study in Mediterranean landscape. Biological Conservation, 192, 120129.

Frey-Ehrenbold, A., Bontadina, F., Arlettaz, R. \& Obrist, M.K. (2013) Landscape connectivity, habitat structure and activity of bat guilds in farmland-dominated matrices. Journal of Applied Ecology, 50, 252-261.

Frick, W.F., Baerwald, E.F., Pollock, J.F., Barclay, R.M.R., Szymanski, J.A., Weller, T.J., Russell, A.L., Loeb, S.C., Medellin, R.A. \& McGuire, L.P. (2017) Fatalities at wind turbines may threaten population viability of a migratory bat. Biological Conservation, 209, 172-177.

Froidevaux, J.S.P., Boughey, K.L., Barlow, K.E. \& Jones, G. (2017) Factors driving population recovery of the greater horseshoe bat (Rhinolophus ferrumequinum) in the UK: implications for conservation. Biodiversity and Conservation.

Gibson, L., Wilman, E.N. \& Laurance, W.F. (2017) How Green is ‘Green' Energy? Trends in Ecology and Evolution, 32, 922-935.

Global wind energy council. (2016) Global Wind Report - Annual Market Update 2016.

Hein, C.D., Castleberry, S.B. \& Miller, K. V. (2009) Site-occupancy of bats in relation to forested corridors. Forest Ecology and Management, 257, 1200-1207.

Kelm, D.H., Lenski, J., Kelm, V., Toelch, U. \& Dziock, F. (2014) Seasonal Bat Activity in Relation to Distance to Hedgerows in an Agricultural Landscape in Central Europe and 
Implications for Wind Energy Development. Acta Chiropterologica, 16, 65-73.

Lacoeuilhe, A., Machon, N., Julien, J.F. \& Kerbiriou, C. (2016) Effects of hedgerows on bats and bush crickets at different spatial scales. Acta Oecologica, 71, 61-72.

Maine, J.J. \& Boyles, J.G. (2015) Bats initiate vital agroecological interactions in corn. Proceedings of the National Academy of Sciences, 112, 201505413.

Maxwell, S.L., Fuller, R.A., Brooks, T.M. \& Watson, J.E.M. (2016) The ravages of guns, nets and bulldozers. Nature, 536, 146-145.

Millon, L., Colin, C., Brescia, F. \& Kerbiriou, C. (2018) Wind turbines impact bat activity, leading to high losses of habitat use in a biodiversity hotspot. Ecological Engineering, $112,51-54$.

Millon, L., Julien, J.-F., Julliard, R. \& Kerbiriou, C. (2015) Bat activity in intensively farmed landscapes with wind turbines and offset measures. Ecological Engineering, 75, 250257.

Minderman, J., Gillis, M.H., Daly, H.F. \& Park, K.J. (2017) Landscape-scale effects of single- and multiple small wind turbines on bat activity. Animal Conservation, 1-8.

Minderman, J., Pendlebury, C.J., Pearce-Higgins, J.W. \& Park, K.J. (2012) Experimental evidence for the effect of small wind turbine proximity and operation on bird and bat activity. PloS one, 7, e41177.

Moran, P.A.P. (1950) Notes on Continuous Stochastic Phenomena. Biometrika, 37, 17-23.

Ney-nifle, A.M. \& Mangel, M. (2000) Habitat Loss and Changes in the Species-Area Relationship. Conservation Biology, 14, 893-898.

Obrist, M.K., Boesch, R. \& Fluckiger, P.F. (2004) Variability in echolocation call design of 26 Swiss bat species: consequences, limits and options for automated field identification with a synergetic pattern recognition approach. Mammalia, 68, 307-322.

Rainho, A. \& Palmeirim, J.M. (2011) The importance of distance to resources in the spatial 
modelling of bat foraging habitat. PLoS ONE, 6, 1-10.

Rodrigues, Bach, L., Dubourg-Savage, M., Karapandza, B., Kovac, D., Kervyn, T., Dekker, J., Kepel, A., Bach, P., Collins, J., Harbusch, C., Park, K., Micevski, B. \& Minderman, J. (2015) Guidelines for Consideration of Bats in Wind Farm Projects - Revision 2014. Bonn, Germany.

Roemer, C., Disca, T., Coulon, A. \& Bas, Y. (2017) Bat flight height monitored from wind masts predicts mortality risk at wind farms. Biological Conservation, 215, 116-122.

RTE. (2017) Summary of the French wind energy, http://www.rte-france.com

Rybicki, J. \& Hanski, I. (2013) Species-area relationships and extinctions caused by habitat loss and fragmentation. Ecology Letters, 16, 27-38.

Schaub, A., Ostwald, J. \& Siemers, B.M. (2009) Foraging bats avoid noise. Journal of Experimental Biology, 212, 3036-3036.

Schaub, A. \& Schnitzler, H.-U. (2007) Flight and echolocation behaviour of three vespertilionid bat species while commuting on flyways. Journal of comparative physiology. A, Neuroethology, sensory, neural, and behavioral physiology, 193, 118594.

Schielzeth, H. (2010) Simple means to improve the interpretability of regression coefficients. Methods in Ecology and Evolution, 1, 103-113.

Schnitzler, H.-U. \& Kalko, E.K. V. (2001) Echolocation by Insect-Eating Bats. BioScience, $51,557-569$.

Siemers, B.M. \& Schnitzler, H.-U. (2000) Natterer's bat ( Myotis nattereri Kuhl, 1818) hawks for prey close to vegetation using echolocation signals of very broad bandwidth. Behavioral Ecology and Sociobiology, 47, 400-412.

Sirami, C., Steve, D. \& Cumming, G.S. (2013) Artificial wetlands and surrounding habitats provide important foraging habitat for bats in agricultural landscapes in the Western 
Cape, South Africa. Biological Conservation, 164, 30-38.

Voigt, C.C., Lehnert, L.S., Petersons, G., Adorf, F. \& Bach, L. (2015) Wildlife and renewable energy: German politics cross migratory bats. European Journal of Wildlife Research, 61, 213-219.

Voigt, C.C., Lindecke, O., Schönborn, S., Kramer-Schadt, S. \& Lehmann, D. (2016) Habitat use of migratory bats killed during autumn at wind turbines. Ecological Applications, 26, $771-783$.

Wickramasinghe, L.P., Harris, S., Jones, G. \& Jennings, N.V. (2004) Abundance and species richness of nocturnal insects on organic and conventional farms: Effects of agricultural intensification on bat foraging. Conservation Biology, 18, 1283-1292.

Zuur, A., Ieno, E. \& Elphick, C. (2010) A protocol for data exploration to avoid common statistical problems. Methods in Ecology and Evolution, 1, 3-14.

Zuur, A.F., Ieno, E.N., Walker, N., Saveliev, A.A. \& Smith, G.M. (2009) Mixed Effects Models and Extensions in Ecology with R. 


\section{Supporting information}

Additional Supporting Information may be found in the online version of this article.

Appendix A: sampling design, validations and selection of acoustic data.

Appendix B: additional information about statistical analyses, results and calculation of lost length of hedgerow use by bats. 
Figure 1. Map of the land use, total and studied wind turbines in the study region, showing an example of sampling with simultaneous recordings of bat activity over one night.

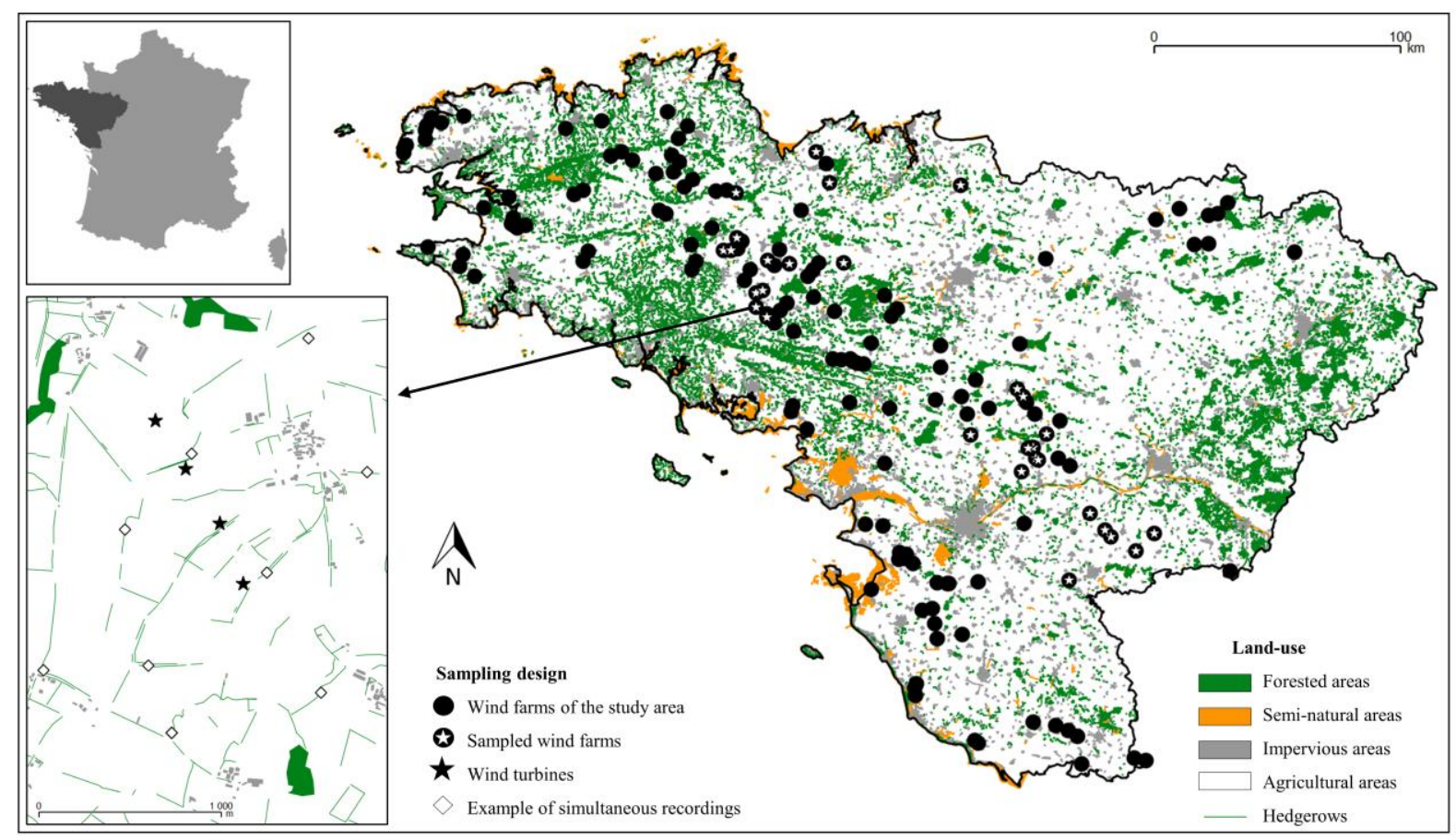

Figure 2. Number of sampled sites across distances between 0 and 1000 metres from the nearest wind turbine.

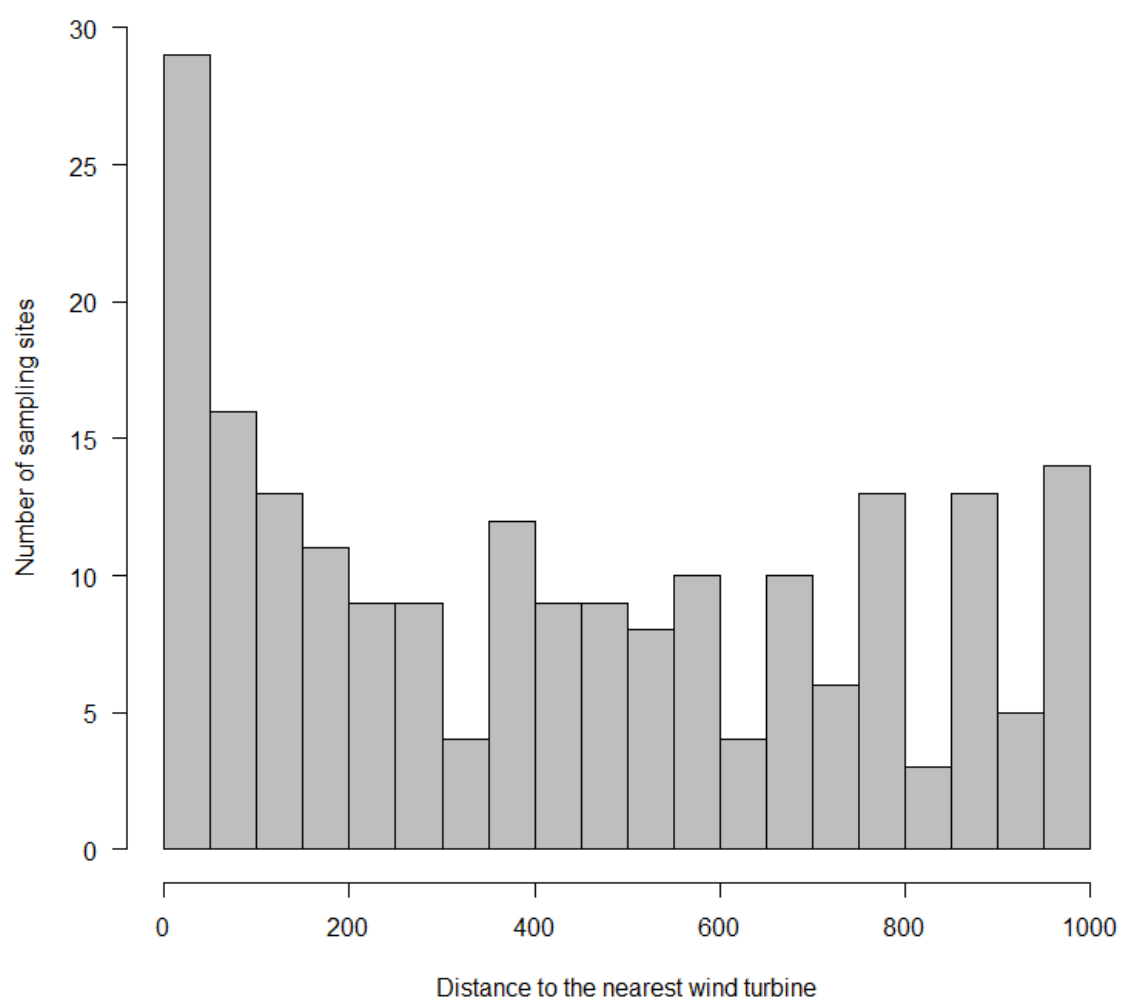


Figure 3. Variation in the predicted number of bat passes as a function of the distances to the nearest wind turbine for species/groups and guilds significantly impacted (black continuous curves). Dotted green curves show the corresponding percentage of the lost activity calculated from the maximum (optimum for $N$. leisleri) predicted bat activity.
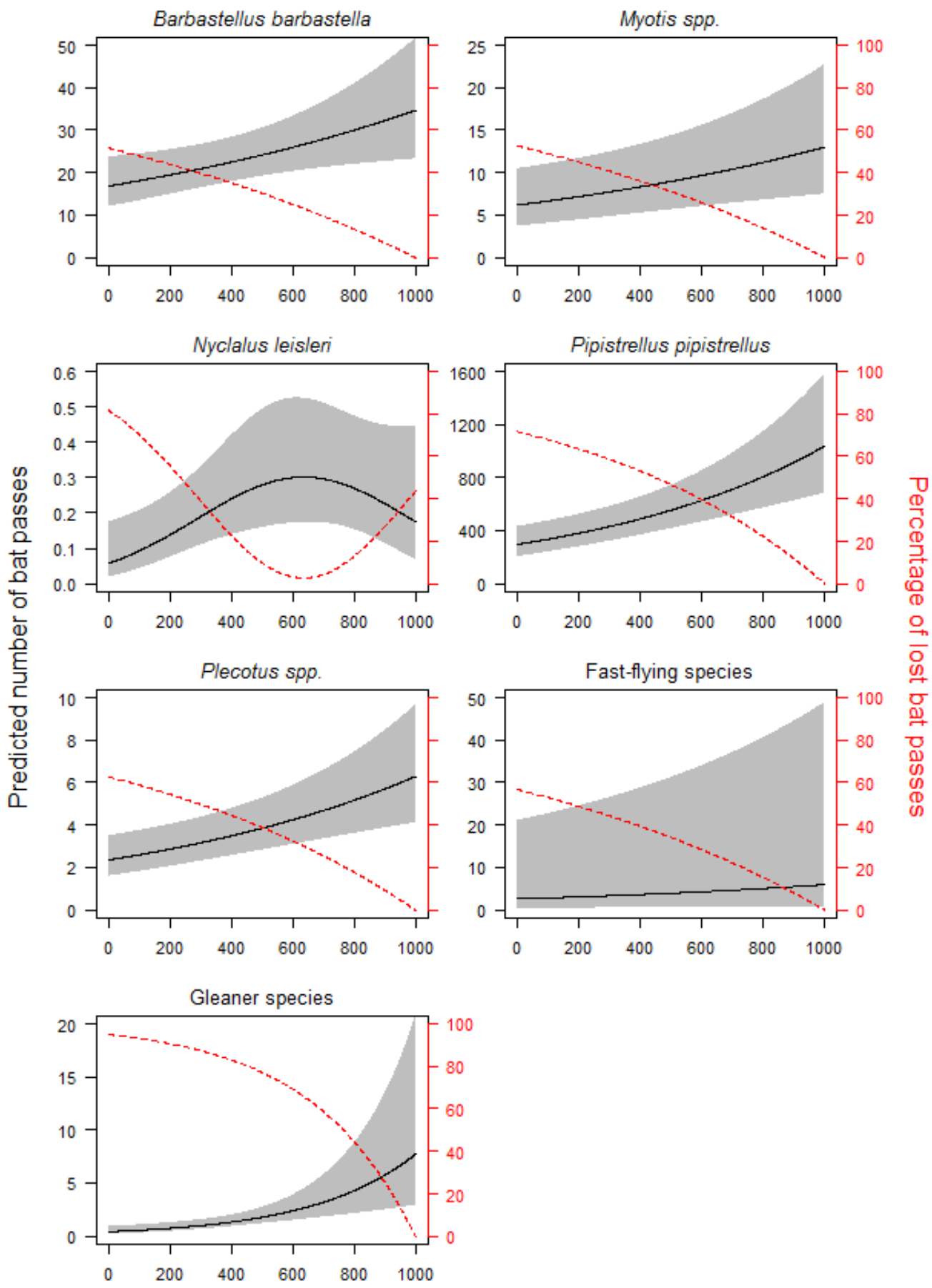

Distance to the nearest wind turbine $(\mathrm{m})$ 
Figure 4. Steps to assess the lost length of hedgerows around a given wind turbine/farm using model predictions. QGIS software was used for the digitization, creation of points and calculation of distances.

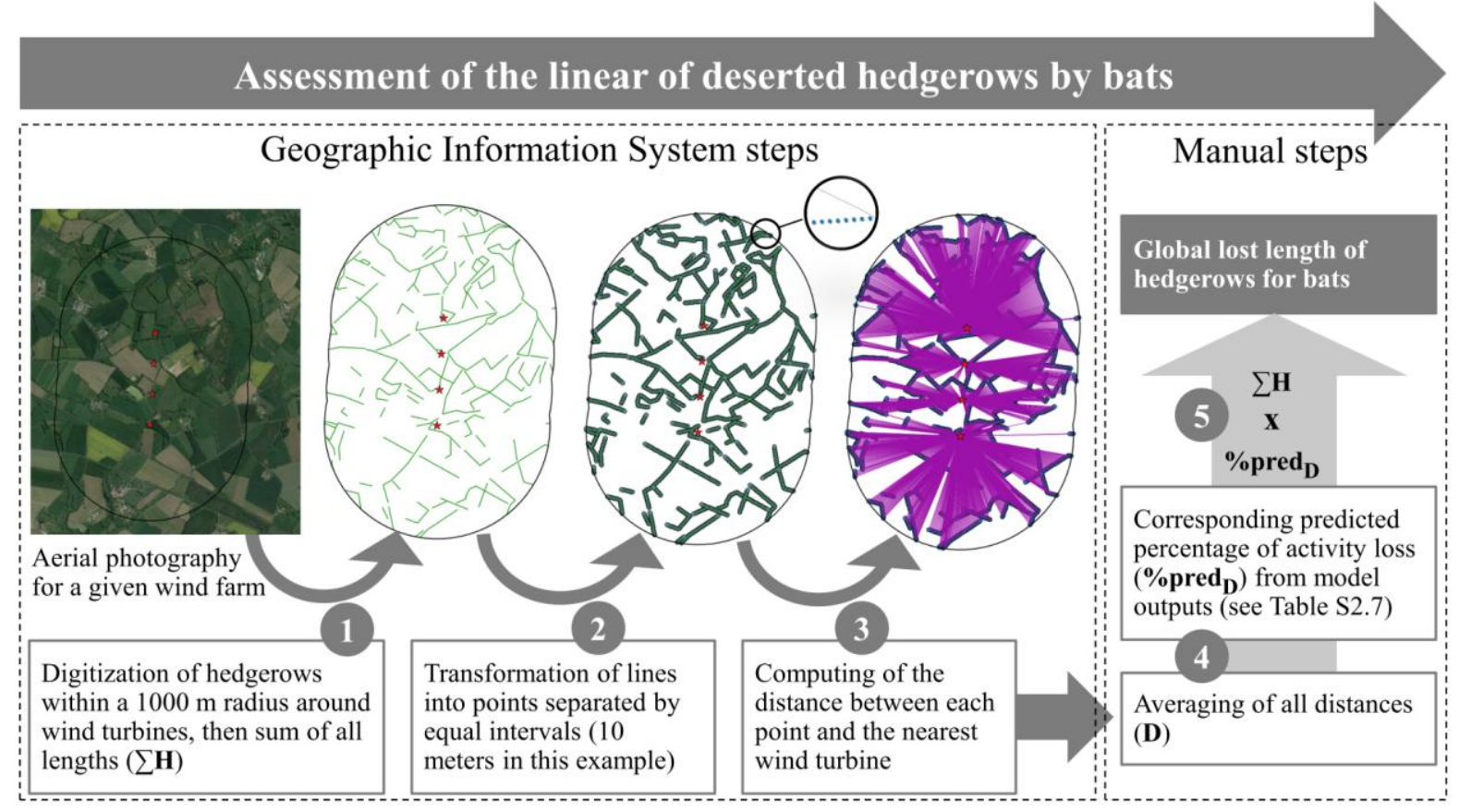


Figure 5. Distances of the 909 established wind turbines in the study region to the nearest wooded edge (forest or hedgerow), overall and for the post-2008 recommendations period. The grey rectangle under the cumulative curves shows the distance range from the nearest wooded edge which should be avoided in turbine installation according to the EUROBATS recommendations.

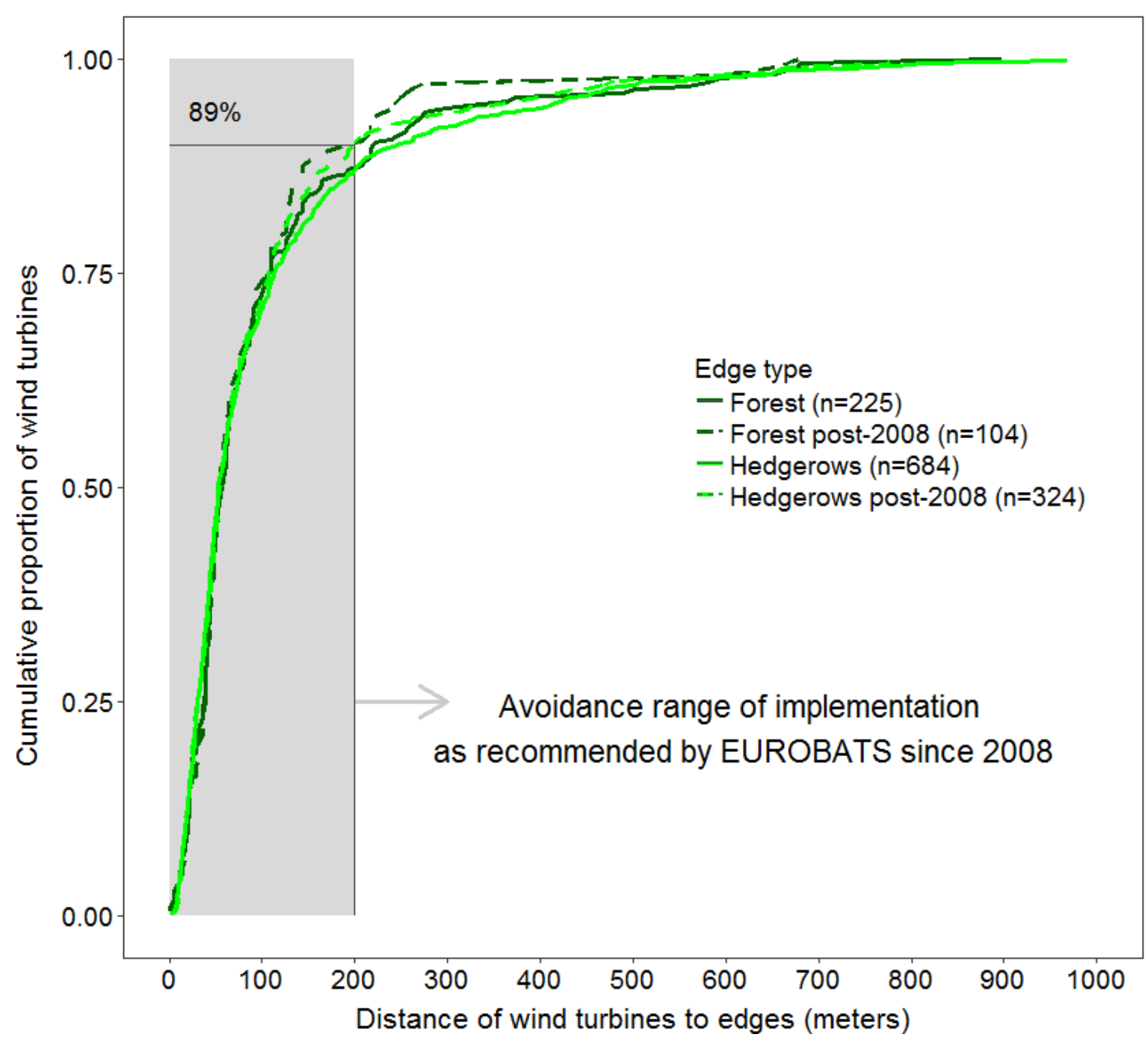


Table 1. Metrics (mean, standard deviation, minimum and maximum) of the raw (not scaled) environmental covariates used in the modelling procedure, according to the buffer size considered for proportion variables.

\begin{tabular}{|c|c|c|c|c|c|c|}
\hline Landscape variables & $\begin{array}{l}\text { Nearest } \\
\text { element }\end{array}$ & $\begin{array}{l}\text { Buffer } \\
(250 \mathrm{~m})\end{array}$ & $\begin{array}{l}\text { Buffer } \\
(500 \mathrm{~m})\end{array}$ & $\begin{array}{l}\text { Buffer } \\
(750 \mathrm{~m})\end{array}$ & $\begin{array}{c}\text { Buffer } \\
(1000 \mathrm{~m})\end{array}$ & $\begin{array}{c}\text { Range } \\
\text { (min-max) }\end{array}$ \\
\hline \multicolumn{7}{|l|}{ Land cover } \\
\hline Length of hedgerows (m) & I & $1032.0 \pm 523.6$ & $3619.0 \pm 1641.5$ & $7797.0 \pm 3158.3$ & $13750.0 \pm 5135.7$ & $84.3-29798.0$ \\
\hline Arable land (\%) & I & $52.9 \pm 28.0$ & $50.4 \pm 20.8$ & $47.7 \pm 16.8$ & $46.5 \pm 14.8$ & $0.0-99.1$ \\
\hline Grass land (\%) & I & $34.6 \pm 27.9$ & $33.8 \pm 20.9$ & $33.9 \pm 18.1$ & $33.3 \pm 16.5$ & $0.0-97.6$ \\
\hline Forest (\%) & I & $1.3 \pm 3.8$ & $2.1 \pm 4.1$ & $2.9 \pm 4.5$ & $3.3 \pm 4.6$ & $0.0-26.1$ \\
\hline \multicolumn{7}{|l|}{ Distances } \\
\hline Dist. to wind turbine (m) & $436.4 \pm 318.1$ & I & I & I & I & $8.1-1000.0$ \\
\hline Dist. to forest (m) & $737.2 \pm 520.5$ & I & I & I & I & $53.7-2700.0$ \\
\hline Dist. to urban (m) & $302.3 \pm 165.8$ & I & I & I & I & $6.7-960.4$ \\
\hline Dist. to wetland (m) & $548.2 \pm 367.1$ & l & I & l & / & $1.6-1644.0$ \\
\hline
\end{tabular}

Table 2. Number of bat passes per species/groups and the corresponding percentage of total passes and occurrences (percentage of presence sites among the 207) according to the applied maximum error risk tolerance for data selection (raw data, maximum error risk tolerance of 0.5 and 0.1$)$

\begin{tabular}{|c|c|c|c|c|c|c|c|c|c|}
\hline \multirow{2}{*}{ Species } & \multicolumn{3}{|c|}{ Number of passes recorded } & \multicolumn{3}{|c|}{$\%$ of total passes } & \multicolumn{3}{|c|}{ Occurrence $(\%)$} \\
\hline & Raw & 0.5 & 0.1 & Raw & 0.5 & 0.1 & Raw & 0.5 & 0.1 \\
\hline Pipistrellus pipistrellus & 159386 & 159386 & 159385 & 81 & 81 & 84 & 99 & 99 & 99 \\
\hline Pipistrellus kuhlii/nathusii & 24023 & 23603 & 22122 & 12 & 12 & 12 & 98 & 98 & 97 \\
\hline Barbastella barbastellus & 5479 & 5472 & 5436 & 3 & 3 & 3 & 90 & 90 & 90 \\
\hline Myotis spp. & 5736 & 3802 & 1946 & 3 & 2 & 1 & 90 & 86 & 68 \\
\hline Plecotus spp. & 1092 & 982 & 566 & 1 & 1 & $<1$ & 73 & 72 & 63 \\
\hline Myotis nattereri & 1532 & 974 & 439 & $<1$ & $<1$ & $<1$ & 80 & 67 & 45 \\
\hline Eptesicus serotinus & 579 & 543 & 473 & $<1$ & $<1$ & $<1$ & 47 & 42 & 38 \\
\hline Rhinolophus hipposideros & 125 & 114 & 110 & $<1$ & $<1$ & $<1$ & 16 & 16 & 15 \\
\hline Nyctalus leisleri & 127 & 53 & 4 & $<1$ & $<1$ & $<1$ & 27 & 16 & 2 \\
\hline Rhinolophus ferrumequinum & 22 & 22 & 22 & $<1$ & $<1$ & $<1$ & 7 & 7 & 7 \\
\hline Nyctalus noctula & 346 & 25 & 8 & $<1$ & $<1$ & $<1$ & 29 & 9 & 3 \\
\hline
\end{tabular}


Table 3. Estimates and standard errors of the distance to the nearest wind turbine variable

(linear and quadratic effects) for the 8 species, 3 species-groups and the 2 guilds studied (*** $\mathrm{P}<0.001, * * \mathrm{P}<0.01, * \mathrm{P}<0.05, . \mathrm{P}<0.1)$. Complete results of other covariates can be found in Table S2.6.

\begin{tabular}{llc}
\hline \multirow{2}{*}{$\begin{array}{l}\text { Species } \\
\text { Pipistrellus pipistrellus }\end{array}$} & \multicolumn{1}{c}{$\begin{array}{c}\text { Effect of the distance to the nearest } \\
\text { wind turbine on bat activity }\end{array}$} \\
\cline { 2 - 3 } Pipistrellus kuhlii / nathusii & \multicolumn{1}{c}{ Linear } & Quadratic \\
Barbastella barbastellus & $\mathbf{0 . 4 1 3} \pm \mathbf{0 . 1 0 0} * * *$ & $/$ \\
Myotis spp. & $\mathbf{0 . 2 3 7} \pm \mathbf{0 . 1 0 7} *$ & $/$ \\
Plecotus spp. & $\mathbf{0 . 2 6 0} \pm \mathbf{0 . 0 9 1} * *$ & $/$ \\
Myotis nattereri & $\mathbf{0 . 3 0 9} \pm \mathbf{0 . 0 9 6} * *$ & $/$ \\
Eptesicus serotinus & $0.132 \pm 0.106$ & $/$ \\
Rhinolophus hipposideros & $0.132 \pm 0.169$ & $/$ \\
Nyctalus leislerii & $0.099 \pm 0.223$ & $/$ \\
Rhinolophus ferrumequinum & $0.329 \pm 0.293$ & $\mathbf{- 0 . 4 1 3} \pm \mathbf{0 . 1 9 8} *$ \\
Nyctalus noctula & $0.308 \pm 0.290$ & $-0.575 \pm 0.307$ \\
\hline Fast-flying species & $\mathbf{0 . 3 4 4} \pm \mathbf{0 . 1 2 3} * *$ & $/$ \\
Gleaner species & $\mathbf{0 . 3 3 5} \pm \mathbf{0 . 0 6 8} * * *$ & $/$ \\
\hline
\end{tabular}




\section{SUPPORTING INFORMATION:}

Estimating habitat loss due to wind turbine avoidance by bats: implications for European siting guidance

Appendix A: sampling design, validations and selection of acoustic data

Table A.1. Number of recording points per night according to classes of distance to the nearest wind turbine.

\begin{tabular}{|c|c|c|c|c|c|c|c|c|c|c|c|}
\hline \multirow{2}{*}{$\begin{array}{l}\text { Sampled } \\
\text { dates }\end{array}$} & \multicolumn{10}{|c|}{$\begin{array}{c}\text { Number of recording points per distance classes }(\mathrm{m}) \text { to the nearest } \\
\text { wind turbine }\end{array}$} & \multirow{2}{*}{ Tota } \\
\hline & $\begin{array}{c}0- \\
100\end{array}$ & $\begin{array}{l}101- \\
200\end{array}$ & $\begin{array}{l}201- \\
300\end{array}$ & $\begin{array}{c}301- \\
400\end{array}$ & $\begin{array}{c}401- \\
500\end{array}$ & $\begin{array}{c}501- \\
600\end{array}$ & $\begin{array}{c}601- \\
700\end{array}$ & $\begin{array}{l}701- \\
800\end{array}$ & $\begin{array}{c}801- \\
900\end{array}$ & $\begin{array}{l}901- \\
1000\end{array}$ & \\
\hline 07/09/2015 & 3 & 1 & 1 & 1 & 1 & 1 & 1 & I & I & I & 9 \\
\hline 08/09/2015 & 2 & 1 & 2 & 1 & 1 & 1 & l & I & 1 & I & 9 \\
\hline 09/09/2015 & 1 & 2 & 1 & I & 1 & I & l & I & 1 & I & 5 \\
\hline $12 / 09 / 2015$ & 2 & 2 & 1 & 2 & I & 2 & l & l & l & I & 9 \\
\hline $13 / 09 / 2015$ & I & 2 & 3 & 1 & 1 & I & 1 & 1 & I & I & 9 \\
\hline $16 / 09 / 2015$ & 1 & 2 & 3 & 3 & I & 1 & 2 & I & 1 & I & 13 \\
\hline $17 / 09 / 2015$ & 2 & 1 & I & 2 & 1 & 1 & I & 1 & 1 & I & 9 \\
\hline $18 / 09 / 2015$ & 2 & 1 & 1 & I & 1 & 1 & I & 1 & 1 & 1 & 9 \\
\hline $21 / 09 / 2015$ & 2 & I & 1 & I & 1 & 1 & 1 & 2 & 1 & 1 & 9 \\
\hline $22 / 09 / 2015$ & 1 & 1 & 1 & 1 & 1 & 1 & 1 & 1 & I & 1 & 9 \\
\hline 23/09/2015 & 2 & 1 & I & I & 1 & 1 & 2 & & 1 & 1 & 9 \\
\hline $24 / 09 / 2015$ & 3 & I & I & I & I & I & 1 & 2 & 1 & 2 & 9 \\
\hline $25 / 09 / 2015$ & 3 & 1 & 1 & 1 & I & I & I & 1 & 1 & 1 & 9 \\
\hline 26/09/2015 & 3 & 1 & I & I & 1 & 1 & I & I & 1 & 2 & 9 \\
\hline $27 / 09 / 2015$ & 2 & 1 & I & I & 1 & 1 & I & 1 & I & 3 & 9 \\
\hline $28 / 09 / 2015$ & 2 & I & l & I & 1 & 1 & 1 & 2 & 1 & 1 & 9 \\
\hline 29/09/2015 & 3 & 1 & 1 & 1 & I & I & I & 1 & 1 & 1 & 9 \\
\hline $30 / 09 / 2015$ & 1 & 2 & I & I & 2 & 1 & I & 2 & I & 1 & 9 \\
\hline $01 / 10 / 2015$ & 2 & 1 & 1 & I & 1 & 1 & I & 1 & 1 & 1 & 9 \\
\hline $04 / 10 / 2015$ & 1 & 2 & 1 & I & 1 & 1 & I & 1 & 1 & 1 & 9 \\
\hline 05/10/2015 & 1 & I & 1 & 1 & 1 & 1 & 1 & 1 & 1 & 1 & 9 \\
\hline 06/10/2015 & 3 & 1 & I & 1 & 1 & & 2 & 1 & I & I & 9 \\
\hline $08 / 10 / 2015$ & 3 & 1 & 1 & 1 & 1 & 1 & 1 & 1 & 1 & 1 & 9 \\
\hline Total & 45 & 24 & 18 & 16 & 18 & 18 & 14 & 19 & 16 & 19 & 207 \\
\hline
\end{tabular}


Table A.2. Total bat passes by confidence index classes from the automatic identification, the number of bat passes manually checked and errors noted.

\begin{tabular}{|c|c|c|c|c|c|c|c|c|c|c|}
\hline \multirow{2}{*}{ Species } & \multicolumn{10}{|c|}{ Confidence index classes of the automatic identification } \\
\hline & $0-0.1$ & $0.1-0.2$ & $0.2-0.3$ & $0.3-0.4$ & $0.4-0.5$ & $0.5-0.6$ & $0.6-0.7$ & $0.7-0.8$ & $0.8-0.9$ & $0.9-1$ \\
\hline \multicolumn{11}{|l|}{ Barbastella barbastellus } \\
\hline Total passes & 3 & 46 & 129 & 216 & 263 & 594 & 868 & 1227 & 1559 & 574 \\
\hline Checked passes & 2 & 25 & 25 & 25 & 25 & 24 & 25 & 25 & 25 & 25 \\
\hline Errors & 2 & 6 & 1 & 0 & 0 & 0 & 0 & 0 & 0 & 0 \\
\hline \multicolumn{11}{|l|}{ Eptesicus serotinus } \\
\hline Total passes & 1 & 41 & 75 & 97 & 70 & 143 & 89 & 54 & 9 & 0 \\
\hline Checked passes & 1 & 25 & 25 & 25 & 25 & 25 & 25 & 24 & 10 & I \\
\hline Errors & 1 & 13 & 7 & 0 & 0 & 0 & 0 & 0 & 0 & / \\
\hline \multicolumn{11}{|l|}{ Myotis nattereri } \\
\hline Total passes & 9 & 139 & 193 & 191 & 188 & 331 & 192 & 128 & 136 & 25 \\
\hline Checked passes & 5 & 13 & 3 & 6 & 5 & 5 & 2 & 10 & 23 & 25 \\
\hline Errors & 5 & 12 & 3 & 4 & 2 & 1 & 0 & 1 & 0 & 0 \\
\hline \multicolumn{11}{|l|}{ Myotis spp. } \\
\hline Total passes & 20 & 463 & 760 & 691 & 604 & 1583 & 1051 & 392 & 147 & 25 \\
\hline Checked passes & 14 & 25 & 25 & 25 & 21 & 25 & 25 & 25 & 25 & 25 \\
\hline Errors & 14 & 14 & 6 & 5 & 4 & 0 & 0 & 0 & 0 & 0 \\
\hline \multicolumn{11}{|l|}{ Nyctalus leisleri } \\
\hline Total passes & 2 & 43 & 36 & 30 & 8 & 5 & 3 & 0 & 0 & 0 \\
\hline Checked passes & 3 & 22 & 25 & 25 & 11 & 8 & 9 & 1 & / & I \\
\hline Errors & 2 & 13 & 14 & 13 & 4 & 0 & 0 & 0 & / & I \\
\hline \multicolumn{11}{|l|}{ Nyctalus noctula } \\
\hline Total passes & 0 & 111 & 108 & 80 & 24 & 14 & 5 & 4 & 0 & 0 \\
\hline Checked passes & I & 16 & 15 & 13 & 10 & 25 & 15 & 7 & 1 & I \\
\hline Errors & / & 16 & 14 & 11 & 9 & 7 & 0 & 0 & 0 & I \\
\hline \multicolumn{11}{|l|}{ Pipistrellus kuhlii } \\
\hline Total passes & 8 & 193 & 366 & 603 & 990 & 3015 & 4876 & 8769 & 4854 & 2 \\
\hline Checked passes & 10 & 25 & 25 & 25 & 23 & 25 & 25 & 25 & 25 & 2 \\
\hline Errors & 9 & 10 & 8 & 4 & 2 & 1 & 1 & 0 & 0 & 0 \\
\hline \multicolumn{11}{|l|}{ Pipistrellus nathusii } \\
\hline Total passes & 0 & 11 & 30 & 31 & 69 & 122 & 70 & 14 & 0 & 0 \\
\hline Checked passes & I & 11 & 21 & 18 & 18 & 23 & 25 & 25 & 5 & I \\
\hline Errors & I & 10 & 16 & 13 & 12 & 15 & 15 & 9 & 1 & I \\
\hline \multicolumn{11}{|l|}{ Pipistrellus pipistrellus } \\
\hline Total passes & 2 & 277 & 711 & 1538 & 3098 & 7851 & 13449 & 25338 & 79552 & 27570 \\
\hline Checked passes & 1 & 25 & 25 & 24 & 24 & 25 & 25 & 24 & 25 & 25 \\
\hline Errors & 1 & 1 & 0 & 1 & 1 & 0 & 0 & 1 & 0 & 0 \\
\hline \multicolumn{11}{|l|}{ Plecotus spp. } \\
\hline Total passes & 6 & 120 & 140 & 164 & 142 & 193 & 166 & 110 & 47 & 4 \\
\hline Checked passes & 7 & 25 & 25 & 25 & 25 & 25 & 25 & 25 & 25 & 4 \\
\hline Errors & 4 & 14 & 7 & 2 & 1 & 1 & 0 & 0 & 0 & 0 \\
\hline \multicolumn{11}{|l|}{ Rhinolophus ferrumequinum } \\
\hline Total passes & 0 & 0 & 0 & 0 & 1 & 4 & 3 & 13 & 1 & 0 \\
\hline Checked passes & l & I & I & I & 1 & 4 & 3 & 13 & 1 & l \\
\hline Errors & I & I & I & I & I & 0 & 0 & 0 & 0 & I \\
\hline \multicolumn{11}{|l|}{ Rhinolophus hipposideros } \\
\hline Total passes & 0 & 1 & 1 & 10 & 8 & 16 & 25 & 61 & 3 & 0 \\
\hline Checked passes & l & 1 & 1 & 10 & 8 & 16 & 25 & 61 & 4 & l \\
\hline Errors & 1 & 1 & 1 & 7 & 1 & 0 & 0 & 0 & 0 & 1 \\
\hline
\end{tabular}




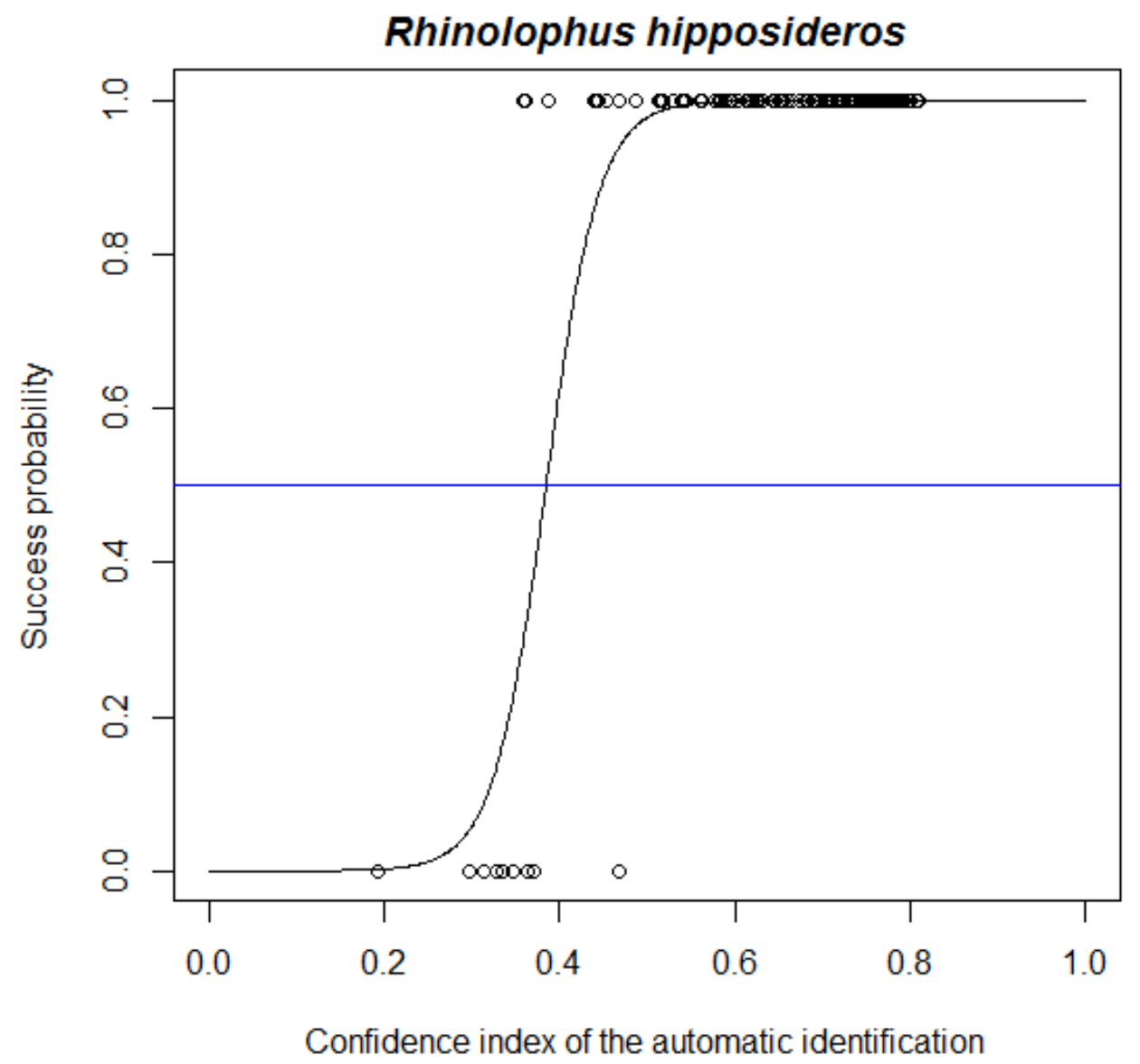

Figure A.1. Example of logistic regression between the success of the automatic identification (binomial distribution) and associated confidence index. The blue line shows a success probability of 0.5 , allowing us to select data with a corresponding confidence index above this threshold. This allows a restriction of the data in order to limit errors and can be performed for higher thresholds, such as 0.8 , for which we confirmed our model results. 
Table A.3. Predicted confidence index of the automatic identification of number of bat passes and occurrences (presence rate over sites) corresponding to the maximal error risk tolerance used for data selection. NA values show error risk probabilities for which it was not possible to predict low risks in automatic identification, due to the low number in manual checking (see Table S1.2).

\begin{tabular}{|c|c|c|c|c|c|c|c|}
\hline \multirow{2}{*}{\multicolumn{2}{|c|}{ Species }} & \multicolumn{6}{|c|}{ Maximum error risk tolerance } \\
\hline & & Raw & 0.5 & 0.4 & 0.3 & 0.2 & 0.1 \\
\hline \multicolumn{8}{|c|}{ Barbastella barbastellus } \\
\hline & Confidence index & / & 0.120 & 0.134 & 0.149 & 0.168 & 0.196 \\
\hline & No. of bat passes & 5479 & 5472 & 5468 & 5466 & 5455 & 5436 \\
\hline & Occurrences & 0.899 & 0.899 & 0.899 & 0.899 & 0.899 & 0.899 \\
\hline \multicolumn{8}{|c|}{ Eptesicus serotinus } \\
\hline & Confidence index & l & 0.181 & 0.201 & 0.222 & 0.247 & 0.286 \\
\hline & No. of bat passes & 579 & 543 & 537 & 526 & 512 & 473 \\
\hline & Occurrences & 0.473 & 0.420 & 0.415 & 0.411 & 0.396 & 0.377 \\
\hline \multicolumn{8}{|c|}{ Myotis spp. } \\
\hline & Confidence index & / & 0.402 & 0.434 & 0.469 & 0.512 & 0.577 \\
\hline & No. of bat passes & 5736 & 3802 & 3597 & 3371 & 3024 & 1946 \\
\hline & Occurrences & 0.899 & 0.860 & 0.845 & 0.821 & 0.787 & 0.681 \\
\hline \multicolumn{8}{|c|}{ Myotis nattereri } \\
\hline & Confidence index & I & 0.418 & 0.456 & 0.497 & 0.548 & 0.624 \\
\hline & No. of bat passes & 1532 & 974 & 893 & 825 & 644 & 439 \\
\hline & Occurrences & 0.797 & 0.667 & 0.643 & 0.594 & 0.536 & 0.454 \\
\hline \multicolumn{8}{|c|}{ Nyctalus leisleri } \\
\hline & Confidence index & I & 0.279 & 0.337 & 0.401 & 0.418 & 0.594 \\
\hline & No. of bat passes & 127 & 53 & 32 & 16 & 12 & 4 \\
\hline & Occurrences & 0.256 & 0.155 & 0.121 & 0.063 & 0.053 & 0.019 \\
\hline \multicolumn{8}{|c|}{ Nyctalus noctula } \\
\hline & Confidence index & I & 0.484 & 0.508 & 0.534 & 0.566 & 0.614 \\
\hline & No. of bat passes & 346 & 25 & 21 & 15 & 10 & 8 \\
\hline & Occurrences & 0.285 & 0.092 & 0.082 & 0.063 & 0.043 & 0.034 \\
\hline \multicolumn{8}{|c|}{ Pipistrellus kuhlii } \\
\hline & Confidence index & / & 0.165 & 0.217 & 0.273 & 0.342 & 0.445 \\
\hline & No. of bat passes & 23676 & 23563 & 23432 & 23219 & 22914 & 22122 \\
\hline & Occurrences & 0.981 & 0.981 & 0.981 & 0.976 & 0.976 & 0.971 \\
\hline \multicolumn{8}{|c|}{ Pipistrellus nathusii } \\
\hline & Confidence index & I & 0.652 & 0.758 & NA & NA & NA \\
\hline & No. of bat passes & 347 & 40 & 2 & 0 & 0 & 0 \\
\hline & Occurrences & 0.449 & 0.135 & 0.010 & 0.000 & 0.000 & 0.000 \\
\hline \multicolumn{8}{|c|}{ Pipistrellus pipistrellus } \\
\hline & Confidence index & I & 0.000 & 0.000 & 0.000 & 0.000 & 0.097 \\
\hline & No. of bat passes & 159386 & 159386 & 159386 & 159386 & 159386 & 159385 \\
\hline & Occurrences & 0.986 & 0.986 & 0.986 & 0.986 & 0.986 & 0.986 \\
\hline \multicolumn{8}{|c|}{ Plecotus spp. } \\
\hline & Confidence index & / & 0.187 & 0.238 & 0.295 & 0.363 & 0.466 \\
\hline & No. of bat passes & 1092 & 982 & 934 & 835 & 725 & 566 \\
\hline & Occurrences & 0.734 & 0.715 & 0.715 & 0.710 & 0.657 & 0.628 \\
\hline \multicolumn{8}{|c|}{ Rhinolophus ferrumequinum } \\
\hline & Confidence index & / & 0.000 & 0.000 & 0.000 & 0.000 & 0.000 \\
\hline & No. of bat passes & 22 & 22 & 22 & 22 & 22 & 22 \\
\hline & Occurrences & 0.068 & 0.068 & 0.068 & 0.068 & 0.068 & 0.068 \\
\hline \multicolumn{8}{|c|}{ Rhinolophus hipposideros } \\
\hline & Confidence index & / & 0.386 & 0.399 & 0.412 & 0.428 & 0.453 \\
\hline & No. of bat passes & 125 & 114 & 113 & 113 & 113 & 110 \\
\hline & Occurrences & 0.164 & 0.155 & 0.150 & 0.150 & 0.150 & 0.150 \\
\hline
\end{tabular}




\section{Appendix B: additional information about statistical analyses, results and calculation of lost length of hedgerow use by bats}

Table B.1. Correlation matrix between variables (dist: distance; WT: wind turbine; F: forest;

U: urban; W: wetland; H: hedgerow; GL: grassland; AL: arable land) including the buffer size of the calculation (250, 500, 750 and $1000 \mathrm{~m}$ radius). Only the arable land and grassland variables were highly correlated $(r>0.7)$, and were not simultaneously included in the modelling procedure. Note that despite this correlation check step, we checked for potential collinearity problems in the full models using the Variance Inflation Factor (VIF) before modelling.

\begin{tabular}{|c|c|c|c|c|c|c|c|c|c|c|c|c|c|c|c|c|c|c|c|}
\hline & 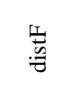 & 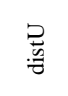 & $\stackrel{3}{3}$ & $\begin{array}{l}\text { Q } \\
\text { İ } \\
\text { In }\end{array}$ & $\begin{array}{l}8 \\
\stackrel{n}{1} \\
\text { : }\end{array}$ & $\begin{array}{l}\stackrel{8}{I} \\
\text { I }\end{array}$ & 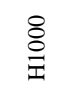 & 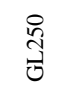 & $\begin{array}{l}8 \\
\stackrel{8}{0} \\
0\end{array}$ & $\stackrel{\circ}{\stackrel{n}{9}}$ & $\frac{8}{8}$ & 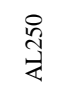 & \begin{tabular}{l}
8 \\
8 \\
3 \\
\multirow{4}{4}{}
\end{tabular} & $\frac{\stackrel{\circ}{\frac{n}{4}}}{\frac{1}{4}}$ & $\frac{8}{8}$ & $\begin{array}{l}\text { ڤે } \\
\text { त्र }\end{array}$ & $\begin{array}{l}8 \\
\text { 点 }\end{array}$ & 点 & $\frac{8}{\frac{8}{1}}$ \\
\hline DistWT & -0.02 & -0.39 & -0.13 & 0.25 & 0.18 & 0.13 & 0.10 & -0.03 & 0.03 & 0.04 & -0.01 & -0.06 & -0.16 & -0.15 & -0.09 & -0.12 & -0.07 & -0.06 & -0.01 \\
\hline DistF & 1.00 & 0.04 & -0.23 & -0.10 & -0.21 & -0.21 & -0.25 & 0.12 & 0.19 & 0.26 & 0.29 & -0.03 & -0.01 & -0.02 & -0.03 & -0.39 & -0.53 & -0.56 & -0.54 \\
\hline DistU & & 1.00 & -0.02 & -0.27 & -0.24 & -0.19 & -0.16 & -0.13 & -0.18 & -0.16 & -0.10 & 0.19 & 0.25 & 0.23 & 0.16 & 0.17 & 0.04 & -0.01 & -0.03 \\
\hline DistW & & & 1.00 & 0.05 & 0.07 & 0.07 & 0.07 & 0.07 & 0.01 & -0.04 & -0.04 & -0.07 & 0.01 & 0.04 & 0.03 & 0.24 & 0.26 & 0.25 & 0.24 \\
\hline $\mathrm{H} 250$ & & & & 1.00 & 0.83 & 0.72 & 0.66 & 0.38 & 0.37 & 0.32 & 0.28 & -0.42 & -0.42 & -0.37 & -0.34 & -0.14 & -0.15 & -0.09 & -0.03 \\
\hline $\mathrm{H} 500$ & & & & & 1.00 & 0.92 & 0.85 & 0.32 & 0.38 & 0.35 & 0.31 & -0.36 & -0.41 & -0.40 & -0.38 & -0.06 & -0.13 & -0.07 & -0.02 \\
\hline H750 & & & & & & 1.00 & 0.95 & 0.30 & 0.35 & 0.34 & 0.30 & -0.35 & -0.39 & -0.38 & -0.36 & 0.03 & -0.09 & -0.09 & -0.05 \\
\hline H1000 & & & & & & & 1.00 & 0.28 & 0.31 & 0.29 & 0.27 & -0.32 & -0.37 & -0.35 & -0.34 & 0.07 & -0.01 & -0.04 & -0.04 \\
\hline GL250 & & & & & & & & 1.00 & 0.88 & 0.73 & 0.65 & -0.94 & -0.82 & -0.68 & -0.59 & -0.11 & -0.16 & -0.17 & -0.21 \\
\hline GL500 & & & & & & & & & 1.00 & 0.92 & 0.83 & -0.82 & -0.91 & -0.85 & -0.76 & -0.17 & -0.24 & -0.23 & -0.26 \\
\hline GL750 & & & & & & & & & & 1.00 & 0.96 & -0.67 & -0.81 & -0.88 & -0.84 & -0.21 & -0.33 & -0.32 & -0.33 \\
\hline GL1000 & & & & & & & & & & & 1.00 & -0.58 & -0.70 & -0.82 & -0.86 & -0.22 & -0.36 & -0.36 & -0.37 \\
\hline AL250 & & & & & & & & & & & & 1.00 & 0.87 & 0.71 & 0.61 & 0.00 & 0.05 & 0.09 & 0.14 \\
\hline AL500 & & & & & & & & & & & & & 1.00 & 0.92 & 0.80 & 0.01 & 0.02 & 0.03 & 0.08 \\
\hline AL750 & & & & & & & & & & & & & & 1.00 & 0.94 & 0.05 & 0.08 & 0.04 & 0.07 \\
\hline AL1000 & & & & & & & & & & & & & & & 1.00 & 0.08 & 0.14 & 0.08 & 0.06 \\
\hline F250 & & & & & & & & & & & & & & & & 1.00 & 0.76 & 0.56 & 0.41 \\
\hline F500 & & & & & & & & & & & & & & & & & 1.00 & 0.85 & 0.69 \\
\hline F750 & & & & & & & & & & & & & & & & & & 1.00 & 0.92 \\
\hline F1000 & & & & & & & & & & & & & & & & & & & 1.00 \\
\hline
\end{tabular}



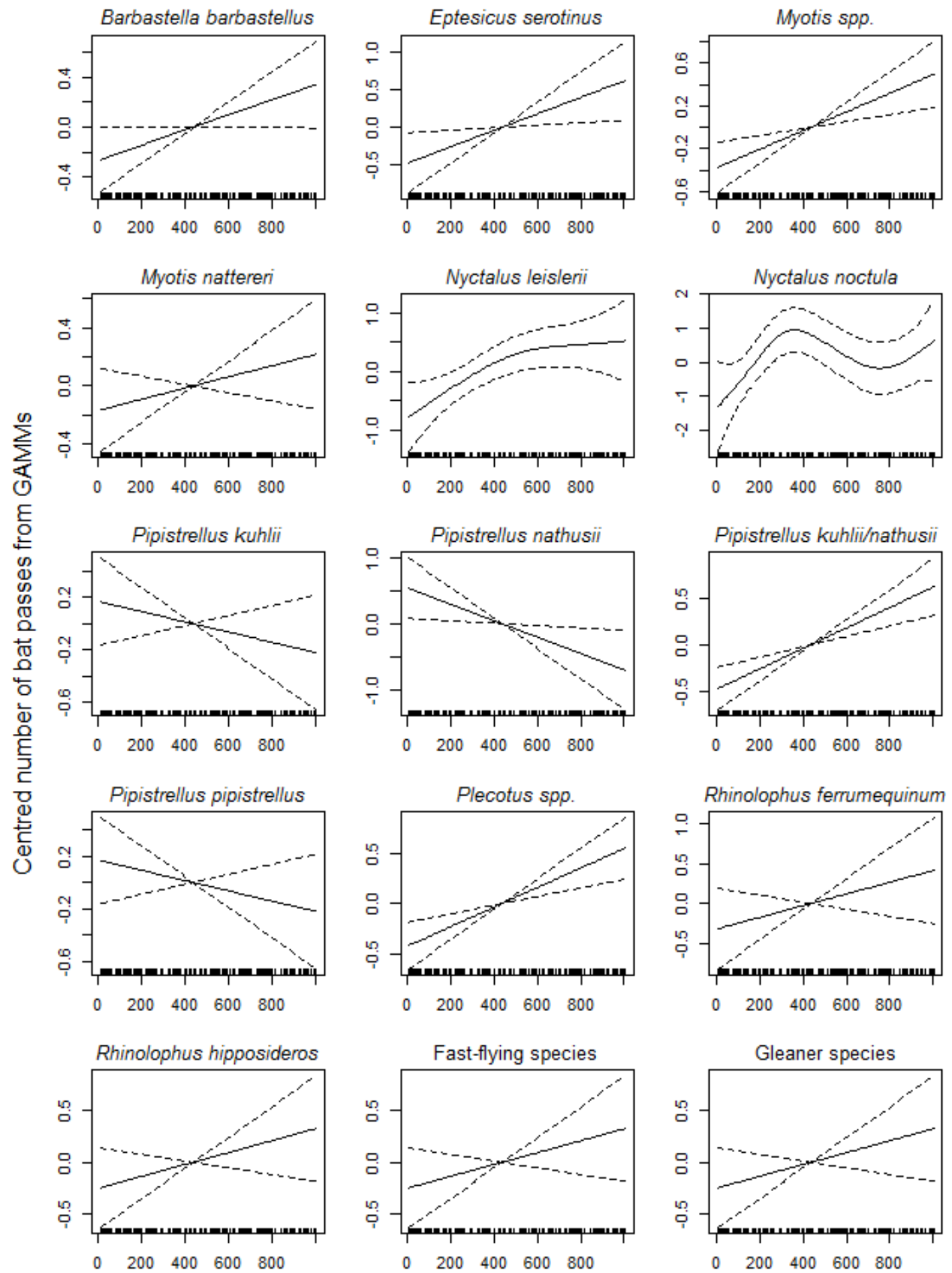

Distance to the nearest wind turbine

Figure B.1. Plots from Generalized Additive Mixed Models (GAMMs) showing the relationship between bat passes and the distance to the nearest turbine variable, to detect nonlinearity cases and to take it into account in Generalized Linear Mixed Models (GLMMs) using a quadratic effect. The $95 \%$ confidence intervals (dotted lines) converge when nonlinear relationship was not detected in the GAMMs. 
Table B.2. Full and best models from the multi-inference model procedure, distribution (NB: negative binomial) and overdispersion ratio (dist: distance; WT: wind turbine; F: forest; U:

urban; W: wetland; H: hedgerow; GL: grassland; AL: arable land, s: scaled variables) according to buffer size $(250,500,750$ and 1000 m radius $)$.

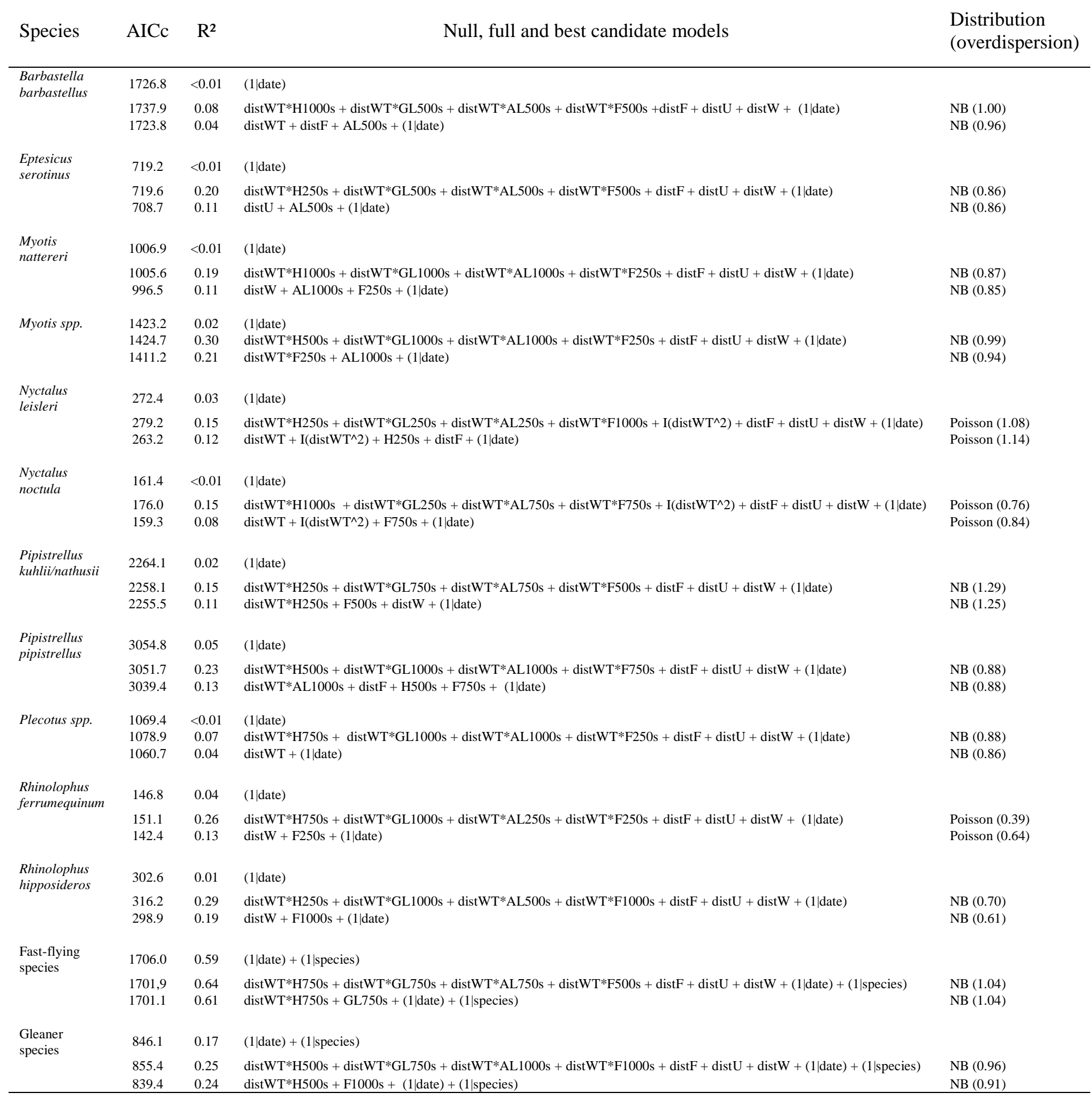


Table B.3. Relative variable importance from model averaging of candidate models with AICc $<2$ and the number of containing models among total of candidate models (dist: distance; WT: wind turbine; F: forest; U: urban; W: wetland; H: hedgerow; GL: grassland; AL: arable land, s: scaled variables).

\begin{tabular}{|c|c|c|c|c|c|c|c|c|c|c|c|c|c|}
\hline \multirow{2}{*}{$\begin{array}{l}\text { Species } \\
\text { (number of top } \\
\text { candidate models with } \\
\text { AICc }<2 \text { ) }\end{array}$} & \multicolumn{13}{|c|}{ Variable importance (number of containing models) } \\
\hline & $\begin{array}{l}\text { Dist } \\
\text { WT }\end{array}$ & $\begin{array}{l}\text { DistWT } \\
\wedge 2\end{array}$ & DistF & DistU & $\begin{array}{l}\text { Dist } \\
\text { W }\end{array}$ & $\begin{array}{c}\text { Leng } \\
\mathrm{hH}\end{array}$ & $\mathrm{AL}$ & GL & $\mathrm{F}$ & $\begin{array}{c}\text { Dist } \\
\text { WT }^{*} \\
\text { Leng } \\
\mathrm{hH}\end{array}$ & $\begin{array}{c}\text { Dist } \\
\mathrm{WT}^{*} \\
\mathrm{AL}\end{array}$ & $\begin{array}{c}\text { Dist } \\
\text { WT* } \\
\text { GL }\end{array}$ & $\begin{array}{c}\text { Dis } \\
\mathrm{tW} \\
\mathrm{T}^{*} \\
\mathrm{~F} \\
\end{array}$ \\
\hline $\begin{array}{l}\text { Barbastella barbastellus } \\
\text { (20) }\end{array}$ & $\begin{array}{c}1 \\
(20)\end{array}$ & I & $\begin{array}{l}0.58 \\
(11)\end{array}$ & $\begin{array}{c}0.35 \\
(7)\end{array}$ & $\begin{array}{c}0.11 \\
(3)\end{array}$ & $\begin{array}{c}0.07 \\
(2)\end{array}$ & $\begin{array}{c}0.45 \\
(9)\end{array}$ & $\begin{array}{c}0.19 \\
(4)\end{array}$ & $\begin{array}{c}0.08 \\
(2)\end{array}$ & I & $\begin{array}{c}0.03 \\
(1)\end{array}$ & I & l \\
\hline $\begin{array}{l}\text { Eptesicus serotinus } \\
\text { (20) }\end{array}$ & $\begin{array}{c}0.25 \\
(6)\end{array}$ & I & $\begin{array}{c}0.43 \\
(9)\end{array}$ & $\begin{array}{c}1 \\
(20)\end{array}$ & $\begin{array}{c}0.13 \\
(3)\end{array}$ & $\begin{array}{c}0.23 \\
(5)\end{array}$ & $\begin{array}{l}0.63 \\
(12)\end{array}$ & $\begin{array}{c}0.14 \\
(3)\end{array}$ & $\begin{array}{c}0.05 \\
(1)\end{array}$ & I & $\begin{array}{c}0.13 \\
(3)\end{array}$ & / & 1 \\
\hline $\begin{array}{l}\text { Myotis nattereri } \\
\text { (9) }\end{array}$ & $\begin{array}{c}1 \\
(9)\end{array}$ & I & I & $\begin{array}{c}0.17 \\
(2)\end{array}$ & $\begin{array}{c}0.81 \\
(7)\end{array}$ & $\begin{array}{c}0.28 \\
(3)\end{array}$ & $\begin{array}{c}0.31 \\
(3)\end{array}$ & $\begin{array}{c}069 \\
(6)\end{array}$ & $1(9)$ & I & l & $\begin{array}{c}0.09 \\
(1)\end{array}$ & $\begin{array}{c}1 \\
(9)\end{array}$ \\
\hline $\begin{array}{l}\text { Myotis spp. } \\
\text { (9) }\end{array}$ & $\begin{array}{c}1 \\
(9)\end{array}$ & I & $\begin{array}{l}0.27 \\
(3)\end{array}$ & I & I & $\begin{array}{l}0.32 \\
(3)\end{array}$ & $\begin{array}{c}0.43 \\
(4)\end{array}$ & $\begin{array}{l}0.48 \\
(4)\end{array}$ & $1(9)$ & I & $\begin{array}{c}0.06 \\
(1)\end{array}$ & 1 & $\begin{array}{l}1 \\
(9)\end{array}$ \\
\hline $\begin{array}{l}\text { Nyctalus leisleri } \\
\text { (14) }\end{array}$ & $\begin{array}{c}1 \\
(14)\end{array}$ & $\begin{array}{c}1 \\
(14)\end{array}$ & $\begin{array}{l}0.74 \\
(10)\end{array}$ & $\begin{array}{c}0.10 \\
(2)\end{array}$ & I & $\begin{array}{c}0.53 \\
(8)\end{array}$ & $\begin{array}{c}0.13 \\
(2)\end{array}$ & $\begin{array}{c}0.29 \\
(4)\end{array}$ & $\begin{array}{c}0.05 \\
(1)\end{array}$ & $\begin{array}{l}0.05 \\
(1)\end{array}$ & I & I & $\begin{array}{c}0.0 \\
5 \\
(1)\end{array}$ \\
\hline $\begin{array}{l}\text { Nyctalus noctula } \\
\text { (11) }\end{array}$ & $\begin{array}{c}1 \\
(11)\end{array}$ & $\begin{array}{c}1 \\
(11)\end{array}$ & $\begin{array}{l}0.65 \\
(7)\end{array}$ & $\begin{array}{c}0.07 \\
(1)\end{array}$ & $\begin{array}{l}0.08 \\
(1)\end{array}$ & $\begin{array}{c}0.07 \\
(1)\end{array}$ & $\begin{array}{c}0.34 \\
(4)\end{array}$ & $\begin{array}{c}0.16 \\
(2)\end{array}$ & $1(11)$ & I & $\begin{array}{c}0.14 \\
(2)\end{array}$ & I & I \\
\hline $\begin{array}{l}\text { Pipistrellus kuhlii/nathusii } \\
\text { (8) }\end{array}$ & $\begin{array}{c}1 \\
(8)\end{array}$ & I & I & I & $\begin{array}{c}0.78 \\
(6)\end{array}$ & $1(8)$ & $\begin{array}{c}0.43 \\
(4)\end{array}$ & I & $\begin{array}{l}0.78 \\
(6)\end{array}$ & $1(8)$ & I & I & $\begin{array}{c}0.2 \\
0 \\
(2)\end{array}$ \\
\hline $\begin{array}{l}\text { Pipistrellus pipistrellus } \\
\text { (12) }\end{array}$ & $\begin{array}{c}1 \\
(12)\end{array}$ & I & $\begin{array}{c}0.14 \\
(2)\end{array}$ & $\begin{array}{c}0.11 \\
(2)\end{array}$ & $\begin{array}{c}0.25 \\
(3)\end{array}$ & $\begin{array}{c}0.23 \\
(3)\end{array}$ & $1(12)$ & 1 & $\begin{array}{c}0.06 \\
(1)\end{array}$ & $\begin{array}{c}0.23 \\
(3)\end{array}$ & $\begin{array}{c}0.41 \\
(5)\end{array}$ & 1 & I \\
\hline $\begin{array}{l}\text { Plecotus spp. } \\
\text { (5) }\end{array}$ & $\begin{array}{c}1 \\
(5)\end{array}$ & I & I & $\begin{array}{c}0.19 \\
(1)\end{array}$ & $\begin{array}{c}0.15 \\
(1)\end{array}$ & $\begin{array}{c}0.18 \\
(1)\end{array}$ & $\begin{array}{c}0.13 \\
(1)\end{array}$ & I & I & I & 1 & 1 & 1 \\
\hline $\begin{array}{l}\text { Rhinolophus ferrumequinum } \\
\text { (18) }\end{array}$ & $\begin{array}{c}0.09 \\
(2)\end{array}$ & 1 & $\begin{array}{c}0.25 \\
(5)\end{array}$ & $\begin{array}{c}0.12 \\
(3)\end{array}$ & $\begin{array}{l}0.57 \\
(10)\end{array}$ & $\begin{array}{c}0.09 \\
(2)\end{array}$ & $\begin{array}{c}0.13 \\
(2)\end{array}$ & $\begin{array}{c}0.37 \\
(7)\end{array}$ & $\begin{array}{l}0.96 \\
(17)\end{array}$ & I & 1 & $\begin{array}{c}0.09 \\
(2)\end{array}$ & \\
\hline $\begin{array}{l}\text { Rhinolophus hipposideros } \\
\text { (9) }\end{array}$ & $\begin{array}{c}0.08 \\
(1)\end{array}$ & I & $\begin{array}{c}0.12 \\
(1)\end{array}$ & $\begin{array}{c}0.20 \\
(2)\end{array}$ & $\begin{array}{c}0.77 \\
(7)\end{array}$ & $\begin{array}{c}0.08 \\
(1)\end{array}$ & $\begin{array}{c}0.08 \\
(1)\end{array}$ & $\begin{array}{c}0.09 \\
(1)\end{array}$ & $1(9)$ & I & 1 & 1 & 1 \\
\hline $\begin{array}{l}\text { Fast-flying species } \\
\text { (6) }\end{array}$ & $\begin{array}{l}1 \\
(6)\end{array}$ & 1 & $\begin{array}{c}0.33 \\
(2)\end{array}$ & $\begin{array}{c}0.11 \\
(1)\end{array}$ & I & $1(6)$ & I & $\begin{array}{c}0.62 \\
(4)\end{array}$ & $\begin{array}{c}0.24 \\
(2)\end{array}$ & $1(6)$ & 1 & 1 & I \\
\hline $\begin{array}{l}\text { Gleaner species } \\
\text { (7) }\end{array}$ & $\begin{array}{c}1 \\
(7)\end{array}$ & 1 & $\begin{array}{c}0.23 \\
(2)\end{array}$ & 1 & $\begin{array}{c}0.11 \\
(1)\end{array}$ & $1(7)$ & $\begin{array}{c}0.10 \\
(1)\end{array}$ & I & $\begin{array}{c}0.68 \\
(5)\end{array}$ & $1(7)$ & I & 1 & $\begin{array}{c}0.1 \\
0 \\
(1)\end{array}$ \\
\hline
\end{tabular}


Table B.4. Check for the results for the distance to the nearest wind turbine variable at lower error risk tolerance (0.1) for data selection performing the same analysis procedure as for the 0.5 threshold. For Rhinolophus hipposideros the variable was not selected in the multi-model inference procedure (n.s.).

\begin{tabular}{|c|c|c|}
\hline \multirow{2}{*}{ Species } & \multicolumn{2}{|c|}{ Maximum error risk tolerance } \\
\hline & 0.5 & 0.1 \\
\hline \multicolumn{3}{|l|}{ Barbastella barbastellus } \\
\hline$\beta \pm(\mathrm{SE})$ & $0.237 \pm 0.107$ & $0.237 \pm 0.107$ \\
\hline p-value & 0.027 & 0.028 \\
\hline \multicolumn{3}{|l|}{ Eptesicus serotinus } \\
\hline$\beta \pm(\mathrm{SE})$ & $0.132 \pm 0.169$ & $0.141 \pm 0.179$ \\
\hline p-value & 0.439 & 0.434 \\
\hline \multicolumn{3}{|l|}{ Myotis nattereri } \\
\hline$\beta \pm(\mathrm{SE})$ & $0.132 \pm 0.106$ & $0.038 \pm 0.044$ \\
\hline p-value & 0.216 & 0.388 \\
\hline \multicolumn{3}{|l|}{ Myotis spp. } \\
\hline$\beta \pm(\mathrm{SE})$ & $0.260 \pm 0.091$ & $0.245 \pm 0.096$ \\
\hline p-value & 0.004 & 0.011 \\
\hline \multicolumn{3}{|l|}{ Pipistrellus kuhlii } \\
\hline$\beta \pm(\mathrm{SE})$ & $-0.004 \pm 0.100$ & $-0.005 \pm 0.103$ \\
\hline p-value & 0.966 & 0.962 \\
\hline \multicolumn{3}{|l|}{ Plecotus spp. } \\
\hline$\beta \pm(\mathrm{SE})$ & $0.309 \pm 0.096$ & $0.233 \pm 0.102$ \\
\hline p-value & 0.001 & 0.023 \\
\hline \multicolumn{3}{|l|}{ Rhinolophus hipposideros } \\
\hline$\beta \pm(\mathrm{SE})$ & $0.099 \pm 0.223$ & n.s. \\
\hline p-value & 0.659 & n.s. \\
\hline \multicolumn{3}{|l|}{ Fast-flying species } \\
\hline$\beta \pm(\mathrm{SE})$ & $0.344 \pm 0.123$ & $0.194 \pm 0.108$ \\
\hline p-value & 0.005 & 0.023 \\
\hline \multicolumn{3}{|l|}{ Gleaner species } \\
\hline$\beta \pm(\mathrm{SE})$ & $0.335 \pm 0.068$ & $0.319 \pm 0.104$ \\
\hline p-value & $<0.001$ & 0.002 \\
\hline
\end{tabular}


Table B.5. Check for the results at the 0.5 threshold for the distance to the nearest wind turbine and their quadratic effect with and without environmental covariates in the models.

\begin{tabular}{|c|c|c|c|c|c|}
\hline \multirow[b]{2}{*}{ Species } & & \multicolumn{2}{|c|}{ Adjusted to covariates } & \multicolumn{2}{|c|}{ Without covariates } \\
\hline & & $\begin{array}{l}\text { Distance to wind } \\
\text { turbine }\end{array}$ & $\begin{array}{c}\text { Distance to } \\
\text { wind turbine }{ }^{\wedge} 2\end{array}$ & $\begin{array}{l}\text { Distance to wind } \\
\text { turbine }\end{array}$ & $\begin{array}{l}\text { Distance to wind } \\
\text { turbine }{ }^{\wedge} 2\end{array}$ \\
\hline \multicolumn{6}{|c|}{ Barbastella barbastellus } \\
\hline & $\beta \pm(\mathrm{SE})$ & $0.237 \pm 0.107$ & I & $0.194 \pm 0.094$ & l \\
\hline & $\mathrm{p}$-value & 0.027 & I & 0.040 & I \\
\hline \multicolumn{6}{|c|}{ Eptesicus serotinus } \\
\hline & $\beta \pm(\mathrm{SE})$ & $0.132 \pm 0.169$ & l & $0.397 \pm 0.169$ & l \\
\hline & p-value & 0.439 & l & 0.019 & l \\
\hline \multicolumn{6}{|c|}{ Myotis nattereri } \\
\hline & $\beta \pm(\mathrm{SE})$ & $0.132 \pm 0.106$ & l & $0.140 \pm 0.107$ & l \\
\hline & $\mathrm{p}$-value & 0.216 & l & 0.191 & I \\
\hline \multicolumn{6}{|c|}{ Myotis spp. } \\
\hline & $\beta \pm(\mathrm{SE})$ & $0.260 \pm 0.091$ & l & $0.284 \pm 0.088$ & l \\
\hline & $\mathrm{p}$-value & 0.004 & I & 0.001 & l \\
\hline \multicolumn{6}{|c|}{ Nyctalus leislerii } \\
\hline & $\beta \pm(\mathrm{SE})$ & $0.537 \pm 0.208$ & $-0.413 \pm 0.198$ & $0.589 \pm 0.196$ & $-0.416 \pm 0.196$ \\
\hline & $\mathrm{p}$-value & 0.010 & 0.038 & 0.003 & $\mathbf{0 . 0 3 4}$ \\
\hline \multicolumn{6}{|c|}{ Nyctalus noctula } \\
\hline & $\beta \pm(\mathrm{SE})$ & $0.308 \pm 0.290$ & $-0.575 \pm 0.307$ & $0.291 \pm 0.267$ & $-0.504 \pm 0.301$ \\
\hline & p-value & 0.290 & 0.062 & 0.277 & 0.094 \\
\hline \multicolumn{6}{|c|}{ Pipistrellus pipistrellus } \\
\hline & $\beta \pm(\mathrm{SE})$ & $0.413 \pm 0.100$ & l & $0.352 \pm 0.096$ & l \\
\hline & $\mathrm{p}$-value & $<0.001$ & I & $<0.001$ & l \\
\hline \multicolumn{6}{|c|}{ Pipistrellus kuhlii / nathusii } \\
\hline & $\beta \pm(\mathrm{SE})$ & $-0.004 \pm 0.100$ & I & $-0.104 \pm 0.102$ & I \\
\hline & $\mathrm{p}$-value & 0.966 & I & 0.307 & l \\
\hline \multicolumn{6}{|c|}{ Plecotus spp. } \\
\hline & $\beta \pm(\mathrm{SE})$ & $0.309 \pm 0.096$ & I & $0.316 \pm 0.094$ & l \\
\hline & p-value & 0.001 & I & 0.001 & l \\
\hline \multicolumn{6}{|c|}{ Rhinolophus ferrumequinum } \\
\hline & $\beta \pm(\mathrm{SE})$ & $0.329 \pm 0.293$ & l & $0.155 \pm 0.222$ & l \\
\hline & $\mathrm{p}$-value & 0.265 & I & 0.485 & I \\
\hline \multicolumn{6}{|c|}{ Rhinolophus hipposideros } \\
\hline & $\beta \pm(\mathrm{SE})$ & $0.099 \pm 0.223$ & l & $0.183 \pm 0.219$ & l \\
\hline & p-value & 0.659 & I & 0.404 & l \\
\hline \multicolumn{6}{|c|}{ Fast-flying species } \\
\hline & $\beta \pm(\mathrm{SE})$ & $0.344 \pm 0.123$ & / & $0.303 \pm 0.138$ & l \\
\hline & $\mathrm{p}$-value & 0.005 & I & 0.028 & l \\
\hline \multicolumn{6}{|c|}{ Gleaner species } \\
\hline & $\beta \pm(\mathrm{SE})$ & $0.335 \pm 0.068$ & I & $0.290 \pm 0.115$ & l \\
\hline & $\mathrm{p}$-value & $<0.001$ & I & 0.012 & I \\
\hline
\end{tabular}


Table B.6. Complete results from model averaging of candidate models with delta AICc < 2, estimates, with the standard error and p-value for each species/group and guild according to the selected scale for proportion covariates (250, 500, 750 and 1000 m radius; dist: distance; WT: wind turbine).

\begin{tabular}{|c|c|c|c|c|c|c|c|c|c|c|c|c|c|}
\hline Main effects & $\mathrm{BB}$ & ES & $\mathrm{MN}$ & Msp & NL & $\mathrm{NN}$ & PKN & PP & Plsp & RF & RH & FF & Gl \\
\hline \multirow[t]{2}{*}{ Dist. to WT } & $0.237 \pm 0.107$ & $0.132 \pm 0.169$ & $0.132 \pm 0.106$ & $0.260 \pm 0.091$ & $0.537 \pm 0.208$ & $0.308 \pm 0.290$ & $-0.004 \pm 0.100$ & $0.413 \pm 0.096$ & $0.309 \pm 0.096$ & $0.329 \pm 0.293$ & $0.099 \pm 0.223$ & $0.34424 \pm 0.123$ & $0.334 \pm 0.068$ \\
\hline & 0.027 & 0.439 & 0.216 & 0.00447 & 0.0102 & 0.29 & 0.966 & $<0.001$ & 0.001 & 0.265 & 0.659 & 0.005 & $<0.001$ \\
\hline \multirow[t]{2}{*}{ Dist. to $\mathrm{WT}^{\wedge} 2$} & 1 & 1 & 1 & I & $-0.413 \pm 0.198$ & $-0.575 \pm 0.307$ & 1 & I & 1 & 1 & 1 & 1 & 1 \\
\hline & 1 & 1 & i & 1 & 0.038 & 0.062 & i & 1 & 1 & 1 & 1 & 1 & I \\
\hline \multirow[t]{2}{*}{ Dist. to forest } & $-0.183 \pm 0.109$ & $-0.303 \pm 0.219$ & 1 & $-0.160 \pm 0.158$ & $0.323 \pm 0.183$ & $-0.603 \pm 0.401$ & 1 & $-0.106 \pm 0.131$ & 1 & $-0.396 \pm 0.353$ & $-0.052 \pm 0.138$ & $0.297 \pm 0.188$ & $-0.153 \pm 0.052$ \\
\hline & 0.096 & 0.168 & 1 & 0.31341 & 0.0799 & 0.135 & 1 & 0.41934 & 1 & 0.265 & 0.708 & 0.115 & 0.003 \\
\hline \multirow[t]{2}{*}{ Dist. to urban } & $0.134 \pm 0.104$ & $-0.553 \pm 0.197$ & $0.103 \pm 0.118$ & 1 & $-0.121 \pm 0.193$ & $0.108 \pm 0.264$ & 1 & $0.054 \pm 0.117$ & $-0.097 \pm 0.100$ & $0.2538 \pm 0.3078$ & $-0.259 \pm 0.198$ & $-0.079 \pm 0.172$ & 1 \\
\hline & 0.2014 & 0.005 & 0.388 & 1 & 0.533 & 0.685 & 1 & 0.64524 & 0.33738 & 0.412 & 0.194 & 0.647 & 1 \\
\hline \multirow{2}{*}{ Dist. to wetland } & $-0.088 \pm 0.112$ & $0.163 \pm 0.163$ & $0.230 \pm 0.123$ & i & 1 & $0.177 \pm 0.243$ & $0.218 \pm 0.116$ & $0.122 \pm 0.110$ & $-0.071 \pm 0.110$ & $-0.472 \pm 0.331$ & $-0.450 \pm 0.252$ & 1 & $0.010 \pm 0.027$ \\
\hline & 0.4365 & 0.319 & 0.063 & 1 & 1 & 0.47 & 0.06 & 0.271 & 0.51958 & 0.156 & 0.076 & 1 & 0.722 \\
\hline \multicolumn{14}{|l|}{ Length of hedgerows } \\
\hline \multirow[t]{2}{*}{250} & I & $0.201 \pm 0.177$ & 1 & 1 & $0.255 \pm 0.180$ & I & $-0.267 \pm 0.123$ & 1 & 1 & 1 & $0.136 \pm 0.280$ & 1 & 1 \\
\hline & 1 & 0.26 & 1 & 1 & 0.1597 & 1 & 0.032 & 1 & 1 & 1 & 0.631 & 1 & 1 \\
\hline \multirow[t]{2}{*}{500} & 1 & 1 & 1 & $-0.169 \pm 0.139$ & 1 & 1 & I & $0.011 \pm 0.145$ & 1 & 1 & 1 & 1 & $-0.093 \pm 0.092$ \\
\hline & 1 & 1 & 1 & 0.22886 & 1 & 1 & 1 & 0.938 & 1 & 1 & 1 & 1 & 0.317 \\
\hline \multirow[t]{2}{*}{750} & 1 & 1 & I & 1 & 1 & 1 & 1 & 1 & $-0.126 \pm 0.137$ & $0.254 \pm 0.340$ & I & $-0.045 \pm 0.197$ & 1 \\
\hline & 1 & i & 1 & i & i & 1 & i & i & 0.359 & 0.458 & i & 0.821 & 1 \\
\hline \multirow[t]{2}{*}{1000} & $0.096 \pm 0.133$ & 1 & $-0.173 \pm 0.158$ & 1 & 1 & $-0.139 \pm 0.324$ & 1 & 1 & 1 & 1 & i & 1 & i \\
\hline & 0.4706 & 1 & 0.277 & 1 & 1 & 0.669 & 1 & 1 & 1 & 1 & 1 & 1 & 1 \\
\hline \multicolumn{14}{|l|}{ Grass land proportion } \\
\hline \multirow{2}{*}{250} & 1 & 1 & 1 & 1 & $0.220 \pm 0.177$ & $-0.239 \pm 0.252$ & 1 & 1 & 1 & 1 & 1 & 1 & 1 \\
\hline & 1 & 1 & 1 & I & 0.2169 & 0.347 & I & i & I & I & I & I & I \\
\hline \multirow[t]{2}{*}{500} & $-0.132 \pm 0.114$ & $0.289 \pm 0.201$ & 1 & 1 & 1 & 1 & 1 & 1 & 1 & 1 & 1 & 1 & 1 \\
\hline & 0.2472 & 0.153 & I & 1 & 1 & I & 1 & I & I & 1 & I & 1 & 1 \\
\hline \multirow[t]{2}{*}{750} & 1 & 1 & 1 & 1 & 1 & 1 & 1 & 1 & 1 & 1 & 1 & $0.364 \pm 0.206$ & 1 \\
\hline & I & 1 & 1 & 1 & 1 & 1 & 1 & 1 & 1 & 1 & 1 & 0.079 & 1 \\
\hline \multirow[t]{2}{*}{1000} & 1 & 1 & $0.485 \pm 0.155$ & $0.373 \pm 0.182$ & 1 & 1 & 1 & 1 & 1 & $0.461 \pm 0.341$ & $-0.251 \pm 0.355$ & 1 & 1 \\
\hline & I & 1 & 0.002 & 0.04128 & 1 & 1 & 1 & 1 & 1 & 0.179 & 0.482 & 1 & 1 \\
\hline \multicolumn{14}{|l|}{ Arable land proportion } \\
\hline \multirow[t]{2}{*}{250} & 1 & 1 & 1 & 1 & $-0.153 \pm 0.172$ & I & 1 & 1 & 1 & $0.275 \pm 0.242$ & 1 & 1 & 1 \\
\hline & 1 & 1 & 1 & 1 & 0.3761 & 1 & 1 & 1 & 1 & 0.258 & 1 & 1 & 1 \\
\hline \multirow[t]{2}{*}{500} & $0.161 \pm 0.108$ & $-0.329 \pm 0.199$ & 1 & I & 1 & i & I & i & I & 1 & $-0.114 \pm 0.277$ & I & I \\
\hline & 0.1364 & 0.099 & 1 & 1 & 1 & 1 & 1 & 1 & 1 & 1 & 0.684 & 1 & 1 \\
\hline \multirow[t]{2}{*}{750} & 1 & 1 & 1 & 1 & I & $0.337 \pm 0.268$ & $0.153 \pm 0.120$ & 1 & 1 & 1 & 1 & 1 & 1 \\
\hline & 1 & 1 & 1 & 1 & 1 & 0.211 & 0.206 & 1 & 1 & 1 & 1 & 1 & 1 \\
\hline 1000 & 1 & 1 & $-0.432 \pm 0.149$ & $-0.297 \pm 0.153$ & 1 & 1 & 1 & $0.339 \pm 0.128$ & $0.055 \pm 0.131$ & 1 & 1 & 1 & $0.010 \pm 0.028$ \\
\hline & I & I & 0.004 & 0.05327 & 1 & 1 & 1 & 0.009 & 0.679 & 1 & 1 & 1 & 0.738 \\
\hline Forest proportion & & & & & & & & & & & & & \\
\hline 250 & I & 1 & $0.299 \pm 0.134$ & $0.226 \pm 0.112$ & 1 & 1 & 1 & 1 & 1 & $-0.211 \pm 0.584$ & 1 & 1 & 1 \\
\hline & 1 & 1 & 0.026 & 0.04546 & I & 1 & 1 & i & I & 0.997 & I & 1 & I \\
\hline 500 & $0.114 \pm 0.107$ & $0.156 \pm 0.175$ & 1 & 1 & 1 & 1 & $0.213 \pm 0.116$ & 1 & 1 & I & 1 & $0.166 \pm 0.186$ & 1 \\
\hline & 0.2897 & 0.376 & 1 & 1 & 1 & 1 & 0.068 & 1 & 1 & 1 & 1 & 0.375 & I \\
\hline 750 & 1 & 1 & 1 & 1 & 1 & $-1.01 \pm 0.597$ & 1 & $-0.053 \pm 0.106$ & 1 & 1 & 1 & 1 & 1 \\
\hline & i & i & i & 1 & 1 & 0.093 & 1 & 0.622 & i & 1 & l & 1 & 1 \\
\hline 1000 & 1 & 1 & 1 & 1 & $-0.632 \mathrm{e}-03 \pm 0.262$ & I & 1 & 1 & 1 & 1 & $0.642 \pm 0.260$ & 1 & $0.212 \pm 0.101$ \\
\hline & 1 & 1 & 1 & 1 & 0.998 & 1 & 1 & 1 & 1 & 1 & 0.014 & 1 & 0.036 \\
\hline
\end{tabular}




\begin{tabular}{|c|c|c|c|c|c|c|c|c|c|c|c|c|c|}
\hline $\begin{array}{l}\text { Interaction of } \\
\text { the distance to } \\
\text { wind turbine }\end{array}$ & $\mathrm{BB}$ & $\mathrm{ES}$ & $\mathrm{MN}$ & Msp & NL & PN & PKN & PP & Plsp & $\mathrm{RF}$ & RH & $\mathrm{FF}$ & Gl \\
\hline \multicolumn{14}{|l|}{ Length of hedgerows } \\
\hline 250 & 1 & 1 & I & 1 & $-0.109 \pm 0.193$ & 1 & $0.289 \pm 0.106$ & 1 & 1 & 1 & I & 1 & 1 \\
\hline & 1 & 1 & I & 1 & 0.574 & 1 & 0.007 & 1 & 1 & 1 & I & 1 & 1 \\
\hline \multirow[t]{2}{*}{500} & I & i & I & 1 & 1 & $0.117 \pm 0.196$ & I & $0.183 \pm 0.103$ & 1 & 1 & I & 1 & $-0.281 \pm 0.069$ \\
\hline & 1 & 1 & I & 1 & 1 & 0.554 & 1 & 0.076 & 1 & 1 & I & / & $<0.001$ \\
\hline \multirow{2}{*}{750} & i & 1 & i & 1 & 1 & 1 & i & 1 & 1 & 1 & i & $-0.311 \pm 0.114$ & 1 \\
\hline & i & i & i & i & i & i & i & i & i & i & i & 0.007 & i \\
\hline \multirow[t]{2}{*}{1000} & 1 & 1 & 1 & 1 & 1 & i & i & i & i & i & i & 1 & i \\
\hline & 1 & 1 & 1 & 1 & 1 & 1 & 1 & 1 & 1 & 1 & 1 & 1 & 1 \\
\hline \multicolumn{14}{|l|}{ Grass land proportion } \\
\hline \multirow{2}{*}{250} & 1 & 1 & I & I & 1 & $-0.452 \pm 0.218$ & 1 & 1 & 1 & 1 & I & I & 1 \\
\hline & 1 & 1 & 1 & 1 & 1 & 0.039 & I & I & 1 & 1 & I & 1 & l \\
\hline \multirow[t]{2}{*}{500} & I & 1 & i & i & 1 & 1 & i & I & 1 & i & I & 1 & i \\
\hline & I & 1 & I & 1 & 1 & 1 & I & I & 1 & 1 & I & 1 & I \\
\hline \multirow{2}{*}{750} & 1 & 1 & I & I & 1 & 1 & I & I & 1 & 1 & I & 1 & I \\
\hline & 1 & 1 & 1 & 1 & 1 & 1 & 1 & 1 & 1 & 1 & I & I & l \\
\hline \multirow[t]{2}{*}{1000} & 1 & 1 & $-0.083 \pm 0.100$ & I & 1 & i & I & 1 & I & $-0.406 \pm 0.227$ & I & 1 & 1 \\
\hline & I & I & 0.410 & I & I & 1 & i & 1 & I & 0.076 & I & i & I \\
\hline \multicolumn{14}{|l|}{ Arable land proportion } \\
\hline \multirow[t]{2}{*}{250} & I & 1 & I & 1 & I & $0.464 \pm 0.212$ & I & 1 & I & 1 & l & 1 & l \\
\hline & 1 & 1 & i & I & 1 & 0.03 & I & 1 & I & I & I & 1 & 1 \\
\hline \multirow[t]{2}{*}{500} & $0.040 \pm 0.098$ & $-0.274 \pm 0.177$ & I & 1 & 1 & 1 & I & I & 1 & 1 & I & 1 & I \\
\hline & 0.685 & 0.126 & i & 1 & 1 & i & I & 1 & I & I & I & 1 & 1 \\
\hline \multirow[t]{2}{*}{750} & 1 & 1 & 1 & 1 & 1 & 1 & i & 1 & 1 & i & 1 & 1 & 1 \\
\hline & 1 & 1 & I & 1 & 1 & 1 & I & 1 & 1 & 1 & I & 1 & I \\
\hline \multirow[t]{2}{*}{1000} & I & 1 & I & $-0.038 \pm 0.092$ & 1 & 1 & I & $-0.131 \pm 0.094$ & 1 & 1 & I & I & I \\
\hline & 1 & 1 & 1 & 0.681 & 1 & i & i & 0.166 & I & 1 & I & 1 & 1 \\
\hline \multirow{3}{*}{$\begin{array}{l}\text { Forest proportion } \\
250\end{array}$} & & & & & & & & & & & & & \\
\hline & 1 & 1 & $0.298 \pm 0.132$ & $0.207 \pm 0.102$ & 1 & 1 & 1 & I & 1 & 1 & I & 1 & 1 \\
\hline & 1 & I & 0.025 & 0.044 & I & 1 & 1 & l & I & 1 & I & 1 & I \\
\hline \multirow{2}{*}{500} & 1 & 1 & 1 & I & 1 & $0.163 \pm 0.173$ & $-0.103 \pm 0.102$ & I & I & 1 & I & 1 & I \\
\hline & i & i & i & 1 & i & 0.348 & 0.316 & i & i & i & i & i & i \\
\hline \multirow[t]{2}{*}{750} & I & 1 & I & 1 & 1 & 1 & 1 & 1 & I & 1 & I & 1 & I \\
\hline & i & i & 1 & 1 & 1 & i & i & i & i & i & i & i & 1 \\
\hline \multirow{2}{*}{1000} & 1 & 1 & 1 & 1 & $-0.332 \pm 0.229$ & 1 & 1 & I & I & 1 & I & 1 & $-0.051 \pm 0.098$ \\
\hline & 1 & 1 & 1 & 1 & 0.149 & 1 & 1 & 1 & 1 & 1 & 1 & 1 & 0.606 \\
\hline
\end{tabular}

(BB: Barbastella barbastellus; ES: Eptesicus serotinus; MN: Myotis nattereri; Msp: Myotis spp.; NL: Nyctalus leislerii; NN: Nyctalus noctula; PKN: Pipistrellus kuhlii/nathusii; PP: Pipistrellus pipistrellus; Plsp: Plecotus spp.; RF: Rhinolophus ferrumequinum; RH: Rhinolophus hipposideros; FF: fast-flying species guild; Gl: gleaner species guild) 
1 Table B.7. Loss of activity in relation to the distance to the nearest wind turbine (distWT),

2 calculated as a percentage of the maximum predicted number of bat passes for a given

3 distance (1-[predicted activity of a given distance / maximum predicted activity]) for

4 significantly affected species (BB: Barbastella barbastellus; Msp: Myotis spp.; NL: Nyctalus

5 leislerii; PP: Pipistrellus pipistrellus; Plsp: Plecotus spp.; FF: fast-flying species guild; Gl:

6 gleaner species guild).

\begin{tabular}{|c|c|c|c|c|c|c|c|}
\hline distWT & BB & Msp & NL & $\mathbf{P P}$ & Plsp & FF & GI \\
\hline 0 & 51.56 & 52.50 & 81.64 & 71.48 & 62.63 & 56.58 & 94.74 \\
\hline 1 & 51.53 & 52.47 & 81.55 & 71.45 & 62.59 & 56.54 & 94.72 \\
\hline 10 & 51.21 & 52.15 & 80.66 & 71.12 & 62.26 & 56.21 & 94.58 \\
\hline 20 & 50.86 & 51.79 & 79.65 & 70.76 & 61.89 & 55.84 & 94.42 \\
\hline 30 & 50.47 & 51.43 & 78.60 & 70.39 & 61.51 & 55.47 & 94.25 \\
\hline 40 & 50.11 & 51.07 & 77.52 & 70.02 & 61.13 & 55.10 & 94.08 \\
\hline 50 & 49.71 & 50.70 & 76.40 & 69.64 & 60.75 & 54.73 & 93.90 \\
\hline 60 & 49.34 & 50.33 & 75.24 & 69.25 & 60.36 & 54.35 & 93.72 \\
\hline 70 & 48.94 & 49.96 & 74.05 & 68.87 & 59.97 & 53.96 & 93.53 \\
\hline 80 & 48.57 & 49.59 & 72.82 & 68.47 & 59.57 & 53.58 & 93.34 \\
\hline 90 & 48.20 & 49.21 & 71.56 & 68.08 & 59.17 & 53.19 & 93.14 \\
\hline 100 & 47.82 & 48.83 & 70.27 & 67.67 & 58.77 & 52.80 & 92.94 \\
\hline 110 & 47.44 & 48.45 & 68.94 & 67.26 & 58.36 & 52.40 & 92.72 \\
\hline 120 & 47.06 & 48.06 & 67.58 & 66.85 & 57.95 & 52.00 & 92.51 \\
\hline 130 & 46.68 & 47.67 & 66.19 & 66.43 & 57.53 & 51.60 & 92.28 \\
\hline 140 & 46.29 & 47.28 & 64.76 & 66.01 & 57.11 & 51.20 & 92.05 \\
\hline 150 & 45.90 & 46.89 & 63.31 & 65.58 & 56.69 & 50.79 & 91.82 \\
\hline 160 & 45.51 & 46.49 & 61.83 & 65.14 & 56.26 & 50.37 & 91.57 \\
\hline 170 & 45.11 & 46.09 & 60.32 & 64.70 & 55.82 & 49.96 & 91.32 \\
\hline 180 & 44.71 & 45.69 & 58.78 & 64.26 & 55.39 & 49.54 & 91.06 \\
\hline 190 & 44.31 & 45.28 & 57.22 & 63.81 & 54.95 & 49.12 & 90.79 \\
\hline 200 & 43.91 & 44.88 & 55.64 & 63.35 & 54.50 & 48.69 & 90.52 \\
\hline 210 & 43.50 & 44.46 & 54.04 & 62.89 & 54.05 & 48.26 & 90.23 \\
\hline 220 & 43.09 & 44.05 & 52.42 & 62.42 & 53.60 & 47.83 & 89.94 \\
\hline 230 & 42.68 & 43.63 & 50.78 & 61.95 & 53.14 & 47.39 & 89.64 \\
\hline 240 & 42.26 & 43.21 & 49.13 & 61.46 & 52.67 & 46.95 & 89.33 \\
\hline 250 & 41.84 & 42.79 & 47.47 & 60.98 & 52.21 & 46.51 & 89.01 \\
\hline 260 & 41.42 & 42.36 & 45.79 & 60.49 & 51.73 & 46.06 & 88.68 \\
\hline 270 & 41.00 & 41.93 & 44.11 & 59.99 & 51.26 & 45.61 & 88.35 \\
\hline 280 & 40.57 & 41.49 & 42.42 & 59.48 & 50.77 & 45.15 & 88.00 \\
\hline 290 & 40.14 & 41.06 & 40.74 & 58.97 & 50.29 & 44.69 & 87.64 \\
\hline 300 & 39.70 & 40.62 & 39.05 & 58.45 & 49.79 & 44.23 & 87.27 \\
\hline 310 & 39.27 & 40.17 & 37.36 & 57.93 & 49.30 & 43.76 & 86.89 \\
\hline 320 & 38.83 & 39.72 & 35.68 & 57.40 & 48.80 & 43.29 & 86.50 \\
\hline 330 & 38.38 & 39.27 & 34.02 & 56.86 & 48.29 & 42.81 & 86.09 \\
\hline 340 & 37.94 & 38.82 & 32.36 & 56.31 & 47.78 & 42.34 & 85.68 \\
\hline 350 & 37.49 & 38.36 & 30.72 & 55.76 & 47.26 & 41.85 & 85.25 \\
\hline 360 & 37.03 & 37.90 & 29.09 & 55.20 & 46.74 & 41.37 & 84.81 \\
\hline 370 & 36.58 & 37.44 & 27.49 & 54.64 & 46.21 & 40.87 & 84.36 \\
\hline 380 & 36.12 & 36.97 & 25.92 & 54.06 & 45.68 & 40.38 & 83.89 \\
\hline 390 & 35.65 & 36.50 & 24.37 & 53.48 & 45.14 & 39.88 & 83.41 \\
\hline 400 & 35.19 & 36.03 & 22.85 & 52.90 & 44.60 & 39.38 & 82.91 \\
\hline 410 & 34.72 & 35.55 & 21.37 & 52.30 & 44.05 & 38.87 & 82.40 \\
\hline 420 & 34.24 & 35.07 & 19.92 & 51.70 & 43.50 & 38.36 & 81.87 \\
\hline 430 & 33.76 & 34.58 & 18.52 & 51.09 & 42.94 & 37.84 & 81.33 \\
\hline 440 & 33.28 & 34.09 & 17.15 & 50.47 & 42.38 & 37.32 & 80.78 \\
\hline 450 & 32.80 & 33.60 & 15.84 & 49.85 & 41.81 & 36.79 & 80.20 \\
\hline 460 & 32.31 & 33.10 & 14.57 & 49.21 & 41.23 & 36.26 & 79.61 \\
\hline 470 & 31.82 & 32.60 & 13.36 & 48.57 & 40.65 & 35.73 & 79.00 \\
\hline 480 & 31.33 & 32.10 & 12.20 & 47.92 & 40.06 & 35.19 & 78.37 \\
\hline 490 & 30.83 & 31.59 & 11.10 & 47.27 & 39.47 & 34.65 & 77.73 \\
\hline 500 & 30.33 & 31.08 & 10.06 & 46.60 & 38.87 & 34.10 & 77.06 \\
\hline 510 & 29.82 & 30.57 & 9.08 & 45.93 & 38.27 & 33.55 & 76.37 \\
\hline 520 & 29.31 & 30.05 & 8.16 & 45.24 & 37.65 & 32.99 & 75.67 \\
\hline 530 & 28.80 & 29.52 & 7.31 & 44.55 & 37.04 & 32.43 & 74.94 \\
\hline 540 & 28.28 & 29.00 & 6.54 & 43.85 & 36.42 & 31.87 & 74.19 \\
\hline 550 & 27.76 & 28.47 & 5.83 & 43.14 & 35.79 & 31.30 & 73.42 \\
\hline 560 & 27.24 & 27.93 & 5.19 & 42.42 & 35.15 & 30.72 & 72.63 \\
\hline 570 & 26.71 & 27.39 & 4.63 & 41.70 & 34.51 & 30.14 & 71.81 \\
\hline 580 & 26.18 & 26.85 & 4.15 & 40.96 & 33.86 & 29.55 & 70.97 \\
\hline
\end{tabular}




\begin{tabular}{|c|c|c|c|c|c|c|c|}
\hline 590 & 25.65 & 26.30 & 3.74 & 40.22 & 33.21 & 28.96 & 70.10 \\
\hline 600 & 25.11 & 25.75 & 3.41 & 39.46 & 32.55 & 28.37 & 69.21 \\
\hline 610 & 24.56 & 25.20 & 3.16 & 38.70 & 31.88 & 27.77 & 68.29 \\
\hline 620 & 24.02 & 24.64 & 2.99 & 37.92 & 31.21 & 27.16 & 67.34 \\
\hline 630 & 23.46 & 24.08 & 2.89 & 37.14 & 30.53 & 26.55 & 66.36 \\
\hline 640 & 22.91 & 23.51 & 2.88 & 36.35 & 29.84 & 25.94 & 65.36 \\
\hline 650 & 22.35 & 22.94 & 2.94 & 35.54 & 29.14 & 25.32 & 64.32 \\
\hline 660 & 21.79 & 22.36 & 3.09 & 34.73 & 28.44 & 24.69 & 63.25 \\
\hline 670 & 21.22 & 21.78 & 3.31 & 33.90 & 27.74 & 24.06 & 62.16 \\
\hline 680 & 20.65 & 21.20 & 3.62 & 33.07 & 27.02 & 23.43 & 61.03 \\
\hline 690 & 20.07 & 20.61 & 4.00 & 32.22 & 26.30 & 22.79 & 59.86 \\
\hline 700 & 19.49 & 20.02 & 4.46 & 31.37 & 25.57 & 22.14 & 58.66 \\
\hline 710 & 18.91 & 19.42 & 4.99 & 30.50 & 24.83 & 21.49 & 57.43 \\
\hline 720 & 18.32 & 18.82 & 5.60 & 29.62 & 24.09 & 20.83 & 56.15 \\
\hline 730 & 17.73 & 18.21 & 6.29 & 28.74 & 23.34 & 20.17 & 54.84 \\
\hline 740 & 17.13 & 17.60 & 7.04 & 27.84 & 22.58 & 19.50 & 53.49 \\
\hline 750 & 16.53 & 16.98 & 7.86 & 26.92 & 21.81 & 18.82 & 52.10 \\
\hline 760 & 15.92 & 16.36 & 8.75 & 26.00 & 21.04 & 18.14 & 50.67 \\
\hline 770 & 15.31 & 15.74 & 9.71 & 25.07 & 20.26 & 17.46 & 49.20 \\
\hline 780 & 14.70 & 15.11 & 10.73 & 24.12 & 19.47 & 16.77 & 47.68 \\
\hline 790 & 14.08 & 14.47 & 11.81 & 23.16 & 18.67 & 16.07 & 46.12 \\
\hline 800 & 13.46 & 13.83 & 12.95 & 22.19 & 17.87 & 15.37 & 44.51 \\
\hline 810 & 12.83 & 13.19 & 14.15 & 21.21 & 17.06 & 14.66 & 42.85 \\
\hline 820 & 12.20 & 12.54 & 15.40 & 20.22 & 16.24 & 13.94 & 41.14 \\
\hline 830 & 11.56 & 11.89 & 16.70 & 19.21 & 15.41 & 13.22 & 39.38 \\
\hline 840 & 10.92 & 11.23 & 18.04 & 18.19 & 14.57 & 12.49 & 37.57 \\
\hline 850 & 10.27 & 10.57 & 19.43 & 17.16 & 13.73 & 11.76 & 35.71 \\
\hline 860 & 9.62 & 9.90 & 20.87 & 16.11 & 12.87 & 11.02 & 33.78 \\
\hline 870 & 8.97 & 9.22 & 22.34 & 15.05 & 12.01 & 10.28 & 31.80 \\
\hline 880 & 8.31 & 8.55 & 23.84 & 13.98 & 11.14 & 9.52 & 29.77 \\
\hline 890 & 7.64 & 7.86 & 25.38 & 12.89 & 10.26 & 8.77 & 27.67 \\
\hline 900 & 6.97 & 7.17 & 26.95 & 11.79 & 9.37 & 8.00 & 25.51 \\
\hline 910 & 6.30 & 6.48 & 28.54 & 10.68 & 8.48 & 7.23 & 23.28 \\
\hline 920 & 5.62 & 5.78 & 30.16 & 9.55 & 7.57 & 6.46 & 20.99 \\
\hline 930 & 4.93 & 5.08 & 31.79 & 8.41 & 6.66 & 5.67 & 18.63 \\
\hline 940 & 4.24 & 4.37 & 33.44 & 7.25 & 5.74 & 4.88 & 16.19 \\
\hline 950 & 3.55 & 3.65 & 35.11 & 6.08 & 4.80 & 4.08 & 13.69 \\
\hline 960 & 2.85 & 2.93 & 36.78 & 4.90 & 3.86 & 3.28 & 11.11 \\
\hline 970 & 2.14 & 2.21 & 38.47 & 3.69 & 2.91 & 2.47 & 8.45 \\
\hline 980 & 1.44 & 1.48 & 40.15 & 2.48 & 1.95 & 1.65 & 5.72 \\
\hline 990 & 0.72 & 0.74 & 41.84 & 1.25 & 0.98 & 0.83 & 2.90 \\
\hline 1000 & 0.00 & 0.00 & 43.53 & 0.00 & 0.00 & 0.00 & 0.00 \\
\hline
\end{tabular}

